\title{
Estimation of soil parameters over bare agriculture areas from C-band polarimetric SAR data using neural networks
}

\author{
N. Baghdadi ${ }^{1}$, R. Cresson ${ }^{1}$, M. El Hajj ${ }^{1}$, R. Ludwig ${ }^{2}$, and I. La Jeunesse ${ }^{3}$ \\ ${ }^{1}$ IRSTEA, UMR TETIS, 500 rue François Breton, 34093 Montpellier cedex 5, France \\ ${ }^{2}$ Ludwig-Maximilians-Universitaet Muenchen, Department of Geography, Munich, Germany \\ ${ }^{3}$ Université François Rabelais, UMR Citeres, Tours, France \\ Correspondence to: N. Baghdadi (nicolas.baghdadi@teledetection.fr) \\ Received: 10 February 2012 - Published in Hydrol. Earth Syst. Sci. Discuss.: 7 March 2012 \\ Revised: 4 May 2012 - Accepted: 16 May 2012 - Published: 4 June 2012
}

\begin{abstract}
The purpose of this study was to develop an approach to estimate soil surface parameters from C-band polarimetric SAR data in the case of bare agricultural soils. An inversion technique based on multi-layer perceptron (MLP) neural networks was introduced. The neural networks were trained and validated on a noisy simulated dataset generated from the Integral Equation Model (IEM) on a wide range of surface roughness and soil moisture, as it is encountered in agricultural contexts for bare soils. The performances of neural networks in retrieving soil moisture and surface roughness were tested for several inversion cases using or not using a-priori knowledge on soil parameters. The inversion approach was then validated using RADARSAT-2 images in polarimetric mode. The introduction of expert knowledge on the soil moisture (dry to wet soils or very wet soils) improves the soil moisture estimates, whereas the precision on the surface roughness estimation remains unchanged. Moreover, the use of polarimetric parameters $\alpha_{1}$ and anisotropy were used to improve the soil parameters estimates. These parameters provide to neural networks the probable ranges of soil moisture (lower or higher than $0.30 \mathrm{~cm}^{3} \mathrm{~cm}^{-3}$ ) and surface roughness (root mean square surface height lower or higher than $1.0 \mathrm{~cm}$ ). Soil moisture can be retrieved correctly from C-band SAR data by using the neural networks technique. Soil moisture errors were estimated at about $0.098 \mathrm{~cm}^{3} \mathrm{~cm}^{-3}$ without a-priori information on soil parameters and $0.065 \mathrm{~cm}^{3} \mathrm{~cm}^{-3}$ (RMSE) applying a-priori information on the soil moisture. The retrieval of surface roughness is possible only for low and medium values (lower than $2 \mathrm{~cm}$ ). Results show that the precision on the soil roughness estimates was about $0.7 \mathrm{~cm}$. For surface roughness lower than $2 \mathrm{~cm}$, the precision on the
\end{abstract}

soil roughness is better with an RMSE about $0.5 \mathrm{~cm}$. The use of polarimetric parameters improves only slightly the soil parameters estimates.

\section{Introduction}

Soil moisture content is an important parameter in hydrology, agronomy and as a boundary condition for land surface atmospheric interaction. For bare agricultural soils, the radar backscatter is a function of soil moisture and surface roughness and also sensor configuration (radar wavelength, incidence angle, polarization). The possibility of retrieving these soil parameters is insufficiently investigated from Cband polarimetric SAR (synthetic aperture radar) data. However, extensive studies have been conducted to retrieve soil moisture by using mono- or multi-polarization C-band SAR data (e.g. Alvarez-Mozos et al., 2006, 2009; Baghdadi et al., 2002a, 2006a; Rahman et al., 2008; Le Hégarat et al., 2002; Lievens et al., 2011; Mattia et al., 2009; Moran et al., 2004; Paloscia et al., 2008; Satalino et al., 2002; Srivastava et al., 2003; Zribi and Deschambre, 2002). The availability of RADARSAT-2 data (C-band, $\sim 5.3 \mathrm{GHz}$ ) should enable improvements and increase the ability to retrieve soil parameters, based on RADARDAT's capability of providing images in full polarization.

When using only one radar channel (one incidence angle and one polarization), a better estimate of soil moisture is obtained for a SAR configuration that minimizes the effects of surface roughness (low incidence angle) (Ulaby et al., 1978; Le Toan, 1982; Baghdadi et al., 2006a; Zribi 
and Deschambre, 2002). Moreover, Baghdadi et al. (2006a) have shown that the accuracy of the soil moisture estimate does not improve significantly $\left(<0.01 \mathrm{~cm}^{3} \mathrm{~cm}^{-3}\right)$ when two polarizations ( $\mathrm{HH}$ and $\mathrm{HV}, \mathrm{C}-\mathrm{band}$ ) are used instead of only one polarization. Several studies have shown that the best estimates of soil moisture for one polarization and one radar wavelength are obtained with SAR images acquired at both low and high incidence angles. Indeed, the use of two incidence angles $\left(20^{\circ}\right.$ and $40^{\circ}$ for example) allows estimating both soil moisture and surface roughness (e.g. Baghdadi et al., 2006a; Srivastava et al., 2003; Zribi and Deschambre, 2002 ).

Soil moisture and surface roughness can be estimated from SAR images by using physical or statistical models (e.g. Baghdadi et al., 2002a; Merzouki et al., 2011; Rahman et al., 2008). The best known physical model is the Integral Equation Model (IEM) (Fung et al., 1992; Fung, 1994). It simulates the radar backscattering coefficients from SAR and soil parameters (radar wavelength, polarization, incidence angle, surface roughness and soil dielectric constant). The validity domain of IEM in C-band covers the range of roughness values that are commonly encountered for agricultural surfaces $(k \mathrm{rms} \leq 3$, where rms is the root mean square surface height and $k$ the radar wave number $\cong 1.11 \mathrm{~cm}^{-1}$ for a frequency in C-band of $5.3 \mathrm{GHz}$; Fung et al., 1992). Typical rms values of agricultural bare soils ranges from 0.5 to $4 \mathrm{~cm}$. The discrepancies observed between the IEM and the SAR data had encouraged Baghdadi et al. (2006b, 2011) to propose an empirical calibration of IEM model. Statistical models based on experimental measurements are also often used in soil moisture estimation. For bare soils, the most popular statistical models are those developed by Oh et al. (1992, 2002) and Oh (2004) which use an inversion diagram based on either the cross-polarized backscattering coefficient $\sigma^{\circ} \mathrm{HV}$ and the copolarized ratio $\left(\sigma^{\circ} \mathrm{HH} / \sigma^{\circ} \mathrm{VV}\right)$ or the copolarized ratio $\left(\sigma^{\circ} \mathrm{HH} / \sigma^{\circ} \mathrm{VV}\right)$ and the cross-polarized ratio $\left(\sigma^{\circ} \mathrm{VH} / \sigma^{\circ} \mathrm{VV}\right)$. The Dubois model (Dubois et al., 1995) based on the use of multi-polarized radar observations (HH and VV) is also used for estimating soil moisture content. Discrepancies with experimental measurements in agricultural areas were observed in several studies (e.g. Zribi et al., 1997; Baghdadi et al., 2006b).

Due to the importance for numerous hydrologic and agronomic applications, the development of inversion approaches to estimate soil moisture from SAR images remains a great challenge. The estimation of such variables is often a complex and nonlinear process, making it suitable for artificial neural networks (NN) application. The neural networks are an appropriate tool in the retrieval of geophysical parameters from remote sensing data. The quality of the output parameters is directly dependent upon the quality of the data used to train the NN. The most direct way to train a neural network is by using synthetic data generated using empirical or theoretical surface scattering models. While extensive work has been done on the use of neural networks for processing remotely sensed data, only few studies had investigated the potential of NN for soil parameters estimation (e.g. Baghdadi et al., 2002a; Dawson et al., 1997; Notarnicola et al., 2008; Paloscia et al., 2002, 2008, 2010; Santi et al., 2004; Satalino et al., 2002).

Inversion approaches using a priori information on soil parameters were developed to improve soil moisture retrieval from SAR data. Satalino et al. (2002) developed an algorithm to retrieve soil moisture content over smooth bare soils from ERS-SAR data $\left(\mathrm{VV}-23^{\circ}\right)$. The method consists of inverting the IEM model for a restricted roughness range (rms between 0.6 and $1.6 \mathrm{~cm}$ ) by using neural networks. Results indicate that only two soil moisture classes, i.e. dry and wet soils, can be retrieved using ERS data. It is mainly because a same measured radar backscattering coefficient corresponds to several combinations of soil moisture and surface roughness conditions. Mattia et al. (2006) also use a priori information on soil moisture through a water balance model and surface roughness by means of an empirical approach to constrain the inversion of theoretical radar backscattering models. An accuracy of approximately $0.05 \mathrm{~cm}^{3} \mathrm{~cm}^{-3}$ on retrieved soil moisture is obtained. A possibilistic inversion approach which uses the soil roughness uncertainty for retrieving bare surface soil moisture from SAR data was developed by Verhoest et al. (2007). Accuracy less than $0.06 \mathrm{~cm}^{3} \mathrm{~cm}^{-3}$ was obtained for study cases with low surface roughness (rms surface height less than $1 \mathrm{~cm}$ ).

The objective of this study is to develop an inversion technique based on neural networks to estimate soil surface parameters (moisture content and roughness) over bare agricultural areas from fully polarimetric RADARSAT-2 C-band SAR data. The training of the $\mathrm{NN}$ is performed by using simulated radar backscattering coefficients through the IEM. First, soil parameters retrieval from polarimetric data is accomplished by using $\mathrm{NN}$ applied to a simulated dataset from the IEM model. In order to make the IEM simulation realistic, SAR measurement errors are added to the simulated backscattering coefficients. Next, the approach is validated using RADARSAT-2 data. The performance of the inversion technique is studied in introducing a priori information on the soil moisture and/or the surface roughness. This work enables evaluating the potential of polarimetric SAR sensors at C-band for retrieving surface soil parameters. Section 2 gives a review of datasets, and presents the $\mathrm{NN}$ and the inversion methodology. The results are shown in Sect. 3; and finally, Sect. 4 presents the main conclusions.

\section{Material and methods}

\subsection{Synthetic dataset}

The Integral Equation Model (IEM; Fung et al., 1992; Fung, 1994) is used in order to generate a reference dataset for the inversion of SAR data by a NN technique. The backscattering 
IEM model is capable of reproducing the radar signal at $\mathrm{HH}$, HV and VV from SAR parameters (incidence angle and radar wavelength) and soil surface characteristics (dielectric constant and surface roughness). The empirical model developed by Hallikaïnen et al. (1985) is used to link the volumetric water content (mv) to the corresponding complex dielectric constant. This model uses the sand and clay composition of the soil. The description of surface roughness on bare soils in the IEM is currently based on three parameters (Fung, 1994): the correlation function, the correlation length, and the standard deviation of heights (rms).

Many studies have revealed a poor agreement between IEM simulations and measured data (e.g. Baghdadi et al., 2004, 2006b, 2011; Rakotoarivony et al., 1996; Zribi et al., 1997), with deviations of several decibels which renders the inversion results inaccurate. Baghdadi et al. (2006b, 2011) proposed a semi-empirical calibration of the IEM to improve its performance at C-band. A large experimental database composed of SAR images and ground measurements of soil moisture and surface roughness has been used in this calibration. As the correlation length is the least accurate of the parameters (Verhoest et al., 2008) required in the IEM model, Baghdadi et al. (2006b, 2011) proposed to replace the measured correlation length for each SAR configuration (radar wavelength, incidence angle, and polarization) by a fitting parameter (Lopt), so that the IEM model reproduces better the radar backscattering coefficient. The fitting parameter replaces the inaccurate correlation length and empirically calibrates the model. The calibration parameter is found dependent on rms surface height, polarization, and incidence angle $\theta$ (for a given radar wavelength). The validity domain of the calibrated version of IEM at $\mathrm{C}$-band covers a wide range of soil surface conditions and incidence angles: $0.05 \mathrm{~cm}^{3} \mathrm{~cm}^{-3}<\mathrm{mv}<0.45 \mathrm{~cm}^{3} \mathrm{~cm}^{-3}$, $0.3 \mathrm{~cm}<\mathrm{rms}<5 \mathrm{~cm}$ for $\mathrm{HH}$ and $\mathrm{VV}, 0.3 \mathrm{~cm}<\mathrm{rms}<3.6 \mathrm{~cm}$ for $\mathrm{HV}$, and $25^{\circ}<\theta<45^{\circ}$. The use of Gaussian correlation function with the fitting parameter (Lopt) ensures correct physical behaviour of IEM. In Baghdadi et al. (2006b, 2011), the expressions of Lopt for each polarization were given as a function of rms surface height and incidence angle. These expressions were improved using additional SAR datasets:

$$
\begin{aligned}
& \text { Lopt }(\mathrm{rms}, \theta, \mathrm{HH})=0.162 \\
& \quad+3.006(\sin 1.23 \theta)^{-1.494} \mathrm{rms}
\end{aligned}
$$

$\operatorname{Lopt}(\mathrm{rms}, \theta, \mathrm{HV})=0.9157$

$$
+1.2289(\sin 0.1543 \theta)^{-0.3139} \mathrm{rms}
$$

$\operatorname{Lopt}(\mathrm{rms}, \theta, \mathrm{VV})=1.281$

$$
+0.134(\sin 0.19 \theta)^{-1.59} \mathrm{rms}
$$

$\theta$ is in degrees; Lopt and rms are in centimeters. The coefficient of determination $R^{2}$ is 0.98 for $\mathrm{HH}$, and 0.96 for both HV and VV. A small difference between calibrated IEM simulations (using Lopt, Eq. 1) and SAR data (less than $1 \mathrm{~dB}$ ) was observed, with a standard deviation better than $2 \mathrm{~dB}$.

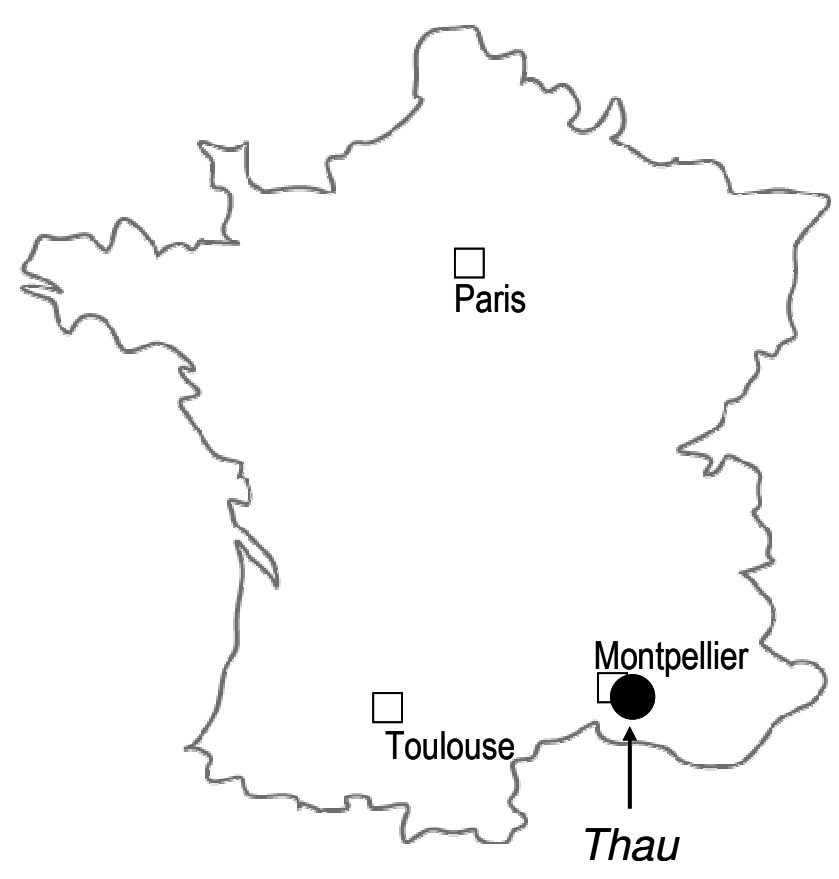

Fig. 1. Location of Thau watershed (France).

A realistic dataset combining a wide range of soil variables (rms surface height "rms" and soil moisture "mv") and corresponding to backscattering coefficients was generated from the calibrated IEM to evaluate the performance of the NN technique. We considered a total of 268110 elements (C-band, HH, HV and VV) corresponding to 331 surface roughness values ( $\mathrm{rms}$ between 0.3 and $3.6 \mathrm{~cm}$ with a step of $0.01 \mathrm{~cm}$ ), 90 soil moisture values (mv between $0.005 \mathrm{~cm}^{3} \mathrm{~cm}^{-3}$ and $0.45 \mathrm{~cm}^{3} \mathrm{~cm}^{-3}$ with a step of $\left.0.005 \mathrm{~cm}^{3} \mathrm{~cm}^{-3}\right)$, and 9 radar incidence angles $(\theta$ between $25^{\circ}$ and $45^{\circ}$ with a step of $2.5^{\circ}$ ). In order to make the IEM simulations more realistic, the SAR measurement error, which includes both calibration errors and measurements precision errors, is added to the simulated backscattering coefficients. Realistic values of measurements errors are between 0.5 and $1 \mathrm{~dB}$ (Satalino et al., 2002). To better simulate an experimental dataset, the synthetic dataset is then obtained by adding a zero mean Gaussian random noise with a standard deviation of \pm 0.5 and $\pm 1 \mathrm{~dB}$ to the simulated backscattering coefficients (in $\mathrm{dB}$ scale). In order to obtain a statistically significant dataset, 100 noise samples are generated for each couple of mv and rms.

\subsection{RADARSAT-2 dataset}

Ten RADARSAT- 2 images in polarimetric mode were acquired over an agricultural site located on the Thau basin near Montpellier in the South of France $\left(43^{\circ} 27^{\prime} \mathrm{N}\right.$ and $3^{\circ} 35^{\prime} \mathrm{E}$ ) (Fig. 1). The study site is mostly composed of agricultural fields intended for growing cereals (wheat) and vineyards, natural vegetation (Mediterranean forest), and 
Table 1. Characteristics of the data set used in this study: images characteristics, number of training plots, range of soil moisture, and soil surface roughness (rms).

\begin{tabular}{|c|c|c|c|c|c|c|}
\hline Date & $\begin{array}{l}\text { Time TU } \\
\text { (hh:mm) }\end{array}$ & $\begin{array}{l}\text { Sensor mode - } \\
\text { Incidence angle }\end{array}$ & Orbit & $\begin{array}{l}\text { Number of } \\
\text { training plots }\end{array}$ & $\begin{array}{c}\text { Soil moisture }(\%) \\
{[\text { min - mean - max }]}\end{array}$ & $\begin{array}{l}\text { Soil roughness } \\
(\mathrm{cm})[\min -\max ]\end{array}$ \\
\hline 18 November 2010 & $05: 55$ & FQ14 - $34.3^{\circ}$ & DES & 11 & {$[9.5-13.3-16.7]$} & {$[0.9-3.3]$} \\
\hline 4 December 2010 & $17: 48$ & $\mathrm{FQ} 26-45.1^{\circ}$ & ASC & 10 & {$[17.0-23.4-33.5]$} & {$[1.2-2.4]$} \\
\hline 12 December 2010 & $05: 55$ & FQ14 - $34.3^{\circ}$ & DES & 10 & {$[9.0-13.7-17.4]$} & {$[1.0-2.4]$} \\
\hline 5 January 2011 & $05: 55$ & $\mathrm{FQ} 14-34.3^{\circ}$ & DES & 0 & - & - \\
\hline 11 January 2011 & $17: 39$ & FQ16 - $36.2^{\circ}$ & ASC & 9 & {$[25.6-28.4-30.2]$} & {$[1.0-2.4]$} \\
\hline 21 January 2011 & $17: 48$ & $\mathrm{FQ} 26-45.1^{\circ}$ & ASC & 10 & {$[9.9-16.5-27.0]$} & {$[1.0-2.4]$} \\
\hline 29 January 2011 & $05: 55$ & FQ14 - $34.3^{\circ}$ & DES & 0 & - & - \\
\hline 22 January 2011 & $05: 55$ & $\mathrm{FQ} 14-34.3^{\circ}$ & DES & 2 & {$[25.3-25.5-25.7]$} & {$[1.3-2.2]$} \\
\hline 15 March 2011 & $05: 43$ & $\mathrm{FQ} 29-47.4^{\circ}$ & DES & 14 & {$[31.2-38.5-45.7]$} & {$[1.1-4.0]$} \\
\hline 18 March 2011 & $05: 55$ & FQ14 - $34.2^{\circ}$ & DES & 16 & {$[18.1-32.0-39.1]$} & {$[1.0-4.0]$} \\
\hline
\end{tabular}

agricultural wasteland. The radar data are available in fine mode with a spatial resolution about $10 \mathrm{~m}$ and incidence angles of $34-36^{\circ}$ and $45-47^{\circ}$ (Table 1). The PolSARPro v4.2.0 software (http://earth.eo.esa.int/polsarpro/) was used for processing the RADARSAT- 2 images $(7 \times 7$ boxcar filter). Then, every generated data layer has been geocoded using the MapReady 2.3 software (http://www.asf.alaska.edu/ downloads/software_tools) and a Digital Elevation Model at pixel spacing of $5 \mathrm{~m}$. The geocoding errors about $60 \mathrm{~m}$ in longitude (X-axis) and $7 \mathrm{~m}$ in latitude (Y-axis) were corrected by a simple translation of images. The co-registration error (about $5 \mathrm{~m}$ after correction) was overcome by removing the boundary pixels (two pixels wide) from each training plot relative to the limits defined by the GPS control points.

In situ measurements of rms surface height and soil moisture (at the 0-5-cm depth) were performed simultaneously to RADARSAT- 2 acquisitions in selected bare training plots (between two and sixteen, Table 1). Training fields were selected with low local topography and at least one hectare in size. The soil moisture of each training field was assumed to be equal to the mean value measured from several samples (between 20 and 50) collected in that field using a calibrated TDR (time domain reflectometry) probe. The soil moistures range from 0.09 to $0.457 \mathrm{~cm}^{3} \mathrm{~cm}^{-3}$. Soil composition is about $52 \%$ silt, $35 \%$ clay, and $12 \%$ sand.

Roughness measurements were made using a needle profilometer ( $1 \mathrm{~m}$ long and with $2 \mathrm{~cm}$ sampling intervals). Ten roughness profiles along and across the direction of tillage (five parallel and five perpendicular) were established in each reference field. From these measurements, the two roughness parameters, root mean square (rms) surface height and correlation length (Lc), were calculated using the mean of all correlation functions. The rms surface heights range from $0.9 \mathrm{~cm}$ to $4.0 \mathrm{~cm}$. The correlation length (Lc) varies from $2 \mathrm{~cm}$ in sown fields to $9 \mathrm{~cm}$ in ploughed fields.

The precision on the two roughness parameters is dependent on the roughness profile length, the number of roughness profiles measurements and the horizontal resolution (sampling interval) of profiles (Lievens et al., 2009; Callens et al., 2006; Oh and Kay, 1998). For ten roughness profiles carried out on each reference field with a profilometer of $1 \mathrm{~m}$ long and a spacing of $2 \mathrm{~cm}$, the accuracy of roughness parameters should be better than $\pm 10 \%$ for rms and between $\pm 10 \%$ and $\pm 20 \%$ for large and small correlation lengths, respectively (Baghdadi et al., 2012).

A small difference was observed between RADARSAT2 data and calibrated IEM simulations (using Lopt, Eq. 1) for $\mathrm{HH}$ and $\mathrm{VV}(-0.8 \mathrm{~dB}$ and $-0.4 \mathrm{~dB}$, respectively), with a RMSE about $2 \mathrm{~dB}(2.0 \mathrm{~dB}$ and $1.9 \mathrm{~dB}$, respectively). The calibrated IEM in HV polarization overestimates the RADARSAT- 2 signal of $1.7 \mathrm{~dB}$, with a RMSE of $2.8 \mathrm{~dB}$. These results are better than those obtained using correlation length measurements. For example, the RMSE of the error observed before the calibration decreased substantially, with the calibrated IEM from $5.0 \mathrm{~dB}$ to $2.0 \mathrm{~dB}$ for $\mathrm{HH}$, from $5.0 \mathrm{~dB}$ to $1.9 \mathrm{~dB}$ for $\mathrm{VV}$, and from $8.3 \mathrm{~dB}$ to $2.8 \mathrm{~dB}$ for $\mathrm{HV}$.

\subsection{Artificial neural networks (ANN)}

Multi-layer perceptron (MLP) neural networks are developed in this study to estimate the soil parameters over bare agricultural soils (moisture content and surface roughness) (Atkinson and Tatnall, 1997; Fine, 1999; Ripley, 1996). Neural networks are trained with the Levenberg-Marquardt algorithm (Marquardt, 1963). The network architecture for the estimation of soil moisture and surface roughness has a threedimensional input vector representing the backscattering coefficients in $\mathrm{HH}, \mathrm{HV}$ and VV polarizations. The two dimensional output vector contains soil moisture and surface roughness. The soil roughness to be estimated corresponds to the soil standard deviation of height rms. The neural network has only one hidden layer. The number of neurons associated with the hidden layer is determined by training the networks. 20 hidden neurons give a good estimate of parameters while keeping a reasonable computing time. To develop a neural network, it is necessary to train the network with a training 
dataset composed of input and output vectors. Training is accomplished to minimize the mean square error between the predicted ANN outputs and the reference values. The ANN models were developed using Matlab software.

The use of simple inversion technique based on simulated look-up tables (IEM model), which minimizes a mean distance (cost function) between the simulated and the measured backscattering coefficients ( $\mathrm{HH}, \mathrm{HV}$ and VV polarizations), does not lead to estimate correctly the soil parameters. Indeed, several minima are sometimes found for the cost function with very close values. Thus, the minimum minimorum does not correspond always to optimum values of soil moisture and surface roughness.

\subsection{Methodological overview}

The synthetic dataset of IEM simulations is divided into equal amounts, where $50 \%$ of the synthetic dataset is used for the training of the neural networks, and the remaining $50 \%$ is used for the validation of networks. The neural networks are first trained on an IEM simulation dataset using the fitting/calibration parameter (Lopt) (Sect. 2.1). The outputs of the network are compared with synthetic and, ultimately, real (RADARSAT-2) data.

In order to improve the soil moisture estimates, a priori knowledge about soil moisture and/or surface roughness is introduced. Indeed, the polarimetric parameters $\alpha_{1}$ (alpha angle that corresponds to the first eigenvector of coherency matrix) and anisotropy $(A)$ can be used to provide thresholds on the possible values of mv and rms, respectively. Baghdadi et al. (2012) showed that the use of $\alpha_{1}$ allows separation of the very wet soils $\left(\alpha_{1} \geq 10^{\circ}\right)$ from the rest with a threshold on mv of $0.30 \mathrm{~cm}^{3} \mathrm{~cm}^{-3}$. Moreover, the anisotropy can be used to discriminate two surface roughness classes, smooth soils with $k \mathrm{rms}<1.0(A<0.3)$ and the rest. Moreover, it is possible to determine the degree of the soil moisture from weather forecasts (precipitation and temperature) and field knowledge (e.g. soil type) in order to integrate in the inversion process the a priori knowledge on the soil moisture range: dry to wet soils $\left(\mathrm{mv}<0.3 \mathrm{~cm}^{3} \mathrm{~cm}^{-3}\right)$ or very wet soils ( $\left.\mathrm{mv} \geq 0.3 \mathrm{~cm}^{3} \mathrm{~cm}^{-3}\right)$. The integration of a priori information constrains the range of possible soil parameter values and thus leads to a better estimation of soil parameters.

Neural networks are built in either using or neglecting a priori information on soil parameters. Four cases were defined:

- Case 1: no a priori information on mv and rms

- Case 2: a priori information on mv. For this case, two neural networks were developed, one for dry to wet soils and one for very wet soils. An overlapping of $0.10 \mathrm{~cm}^{3} \mathrm{~cm}^{-3}$ on $\mathrm{mv}$ was used between the datasets used for the training of these two networks. For dry to wet soils, soil moisture values range from 0.005 to $0.35 \mathrm{~cm}^{3} \mathrm{~cm}^{-3}$ (the mv minimum and the thresh- old plus $0.05 \mathrm{~cm}^{3} \mathrm{~cm}^{-3}$, respectively). In the case of very wet soils, the mv values vary between 0.25 and $0.45 \mathrm{~cm}^{3} \mathrm{~cm}^{-3}$ (the threshold minus $0.05 \mathrm{~cm}^{3} \mathrm{~cm}^{-3}$ and the mv maximum, respectively).

- Case 3: a priori information on rms. Two neural networks were developed, one for smooth to moderate soils and one for moderate to rough soils. An overlapping of $1.0 \mathrm{~cm}$ on rms was used for the training of these two networks. For smooth to moderate soils, surface roughness values vary between 0.3 and $2 \mathrm{~cm}$ (the rms minimum and the threshold plus $0.5 \mathrm{~cm}$, respectively). In the case of moderate to rough soils, rms was between 1 and $3.6 \mathrm{~cm}$ (the threshold minus $0.5 \mathrm{~cm}$ and the $\mathrm{rms}$ maximum, respectively).

- Case 4: a priori information on mv and rms. Four networks were developed, one for dry to wet soils and smooth areas, one for dry to wet soils and rough areas, one for very wet soils and smooth to moderate areas, and one for very wet soils and moderate to rough areas. The mv and rms values of each network are the same as those defined in Cases 2 and 3.

For each studied case (Case 1 to Case 4), only the subdatasets corresponding to rms and $\mathrm{mv}$ values defined by the a priori knowledge are used in the training and the validation phases. For example, for Case 2 with a priori knowledge on $\mathrm{mv}$, two neural networks were developed and validated using the corresponding sub-datasets : sub-dataset_1 corresponding to data with $\mathrm{mv}<35 \%$ and sub-dataset_2 corresponding to data with $\mathrm{mv}>25 \%$.

Moreover, two standard deviations of the measurement error are used for each inversion configuration: \pm 0.5 and $\pm 1 \mathrm{~dB}$ (same measurement error in the training and validation phases). The inversion performance is evaluated using two statistical indexes, the bias and the root mean square error (RMSE):

Bias $=\frac{1}{N} \sum_{i=1}^{N}\left(E_{i}-M_{i}\right)$

$\mathrm{RMSE}=\sqrt{\frac{1}{N} \sum_{i=1}^{N}\left(E_{i}-M_{i}\right)^{2}}$,

where $E$ is the estimated variable, $M$ the measured variable and $N$ the data number. Bias and RMSE are expressed in $\mathrm{cm}^{3} \mathrm{~cm}^{-3}$ or $\%$ for mv, and in $\mathrm{cm}$ for rms.

\section{Evaluation of the inversion approach}

The neural networks developed above have been tested for the evaluation of the precision on soil moisture and surface roughness estimates. Two datasets were used, synthetic (IEM 
Table 2. Inversion approach results for simulated data with measurement errors of \pm 0.5 and $\pm 1 \mathrm{~dB}$. Statistics are given for the estimation of soil moisture (mv) and surface roughness (rms). The format of results is "a/b", where "a" corresponds to statistics using a noise of $\pm 0.5 \mathrm{~dB}$, and " $\mathrm{b}$ " corresponds to statistics using a noise of $\pm 1.0 \mathrm{~dB}$.

\begin{tabular}{|c|c|c|c|c|}
\hline \multirow{2}{*}{$\begin{array}{l}\text { Inversion with measurement } \\
\text { errors of } \pm 0.5 / \pm 1 \mathrm{~dB} \\
\text { No a priori information } \\
\text { on mv and rms }\end{array}$} & \multicolumn{2}{|c|}{ Soil moisture (mv) } & \multicolumn{2}{|c|}{ Surface roughness (rms) } \\
\hline & $\begin{array}{r}\text { Bias } \\
\left(\mathrm{cm}^{3} \mathrm{~cm}^{-3}\right)\end{array}$ & $\begin{array}{r}\text { RMSE } \\
\left(\mathrm{cm}^{3} \mathrm{~cm}^{-3}\right)\end{array}$ & $\begin{array}{l}\text { Bias } \\
(\mathrm{cm})\end{array}$ & $\begin{array}{r}\text { RMSE } \\
(\mathrm{cm})\end{array}$ \\
\hline$\theta=25^{\circ}$ & $0 / 0$ & $0.044 / 0.063$ & $0 / 0$ & $0.53 / 0.70$ \\
\hline$\theta=35^{\circ}$ & $0 / 0$ & $0.058 / 0.071$ & $0 / 0$ & $0.72 / 0.80$ \\
\hline$\theta=45^{\circ}$ & $0 / 0$ & $0.046 / 0.064$ & $0 / 0$ & $0.66 / 0.83$ \\
\hline \multicolumn{5}{|l|}{ A priori information on $\mathrm{mv}$} \\
\hline$\theta=25^{\circ}$ & $0 / 0$ & $0.037 / 0.046$ & $0 / 0$ & $0.50 / 0.64$ \\
\hline$\theta=35^{\circ}$ & $0 / 0$ & $0.044 / 0.049$ & $0 / 0$ & $0.66 / 0.73$ \\
\hline$\theta=45^{\circ}$ & $0 / 0$ & $0.036 / 0.045$ & $0 / 0$ & $0.61 / 0.75$ \\
\hline \multicolumn{5}{|l|}{ A priori information on rms } \\
\hline$\theta=25^{\circ}$ & $0 / 0$ & $0.039 / 0.055$ & $-0.04 /-0.07$ & $0.46 / 0.53$ \\
\hline$\theta=35^{\circ}$ & $0 / 0$ & $0.044 / 0.058$ & $-0.06 /-0.07$ & $0.50 / 0.54$ \\
\hline$\theta=45^{\circ}$ & $0 / 0$ & $0.036 / 0.052$ & $-0.03 /-0.06$ & $0.43 / 0.52$ \\
\hline \multicolumn{5}{|c|}{ A priori information on $\mathrm{mv}$ and $\mathrm{rms}$} \\
\hline$\theta=25^{\circ}$ & $0 / 0$ & $0.035 / 0.043$ & $-0.04 /-0.06$ & $0.45 / 0.51$ \\
\hline$\theta=35^{\circ}$ & $0 / 0$ & $0.036 / 0.043$ & $-0.04 /-0.07$ & $0.47 / 0.52$ \\
\hline$\theta=45^{\circ}$ & $0 / 0$ & $0.031 / 0.041$ & $-0.03 /-0.06$ & $0.43 / 0.51$ \\
\hline
\end{tabular}

simulations) and real datasets (RADARSAT-2 data). The soil parameters estimated using the networks developed above were compared with the reference data.

\subsection{Synthetic dataset}

The inversion approach was first tested on synthetic data in order to study its performance for a large range of soil characteristics (rms and $\mathrm{mv}$ ) and sensor configurations $(\theta)$. In this paper, three incidence angles were studied in detail: $25^{\circ}, 35^{\circ}$, and $45^{\circ}$. These incidences are selected to cover the range of incidence angles available on the satellite SARs.

All statistical indexes were computed to evaluate the performance of the inversion procedure and to determine the retrieval errors on $\mathrm{mv}$ and rms. Table 2 shows the inversion results for the \pm 0.5 and $\pm 1 \mathrm{~dB}$ noise conditions. The three incidence angles analyzed in this study $\left(25^{\circ}, 35^{\circ}\right.$, and $45^{\circ}$ ) showed similar performance on the soil moisture estimation. For example, in the case of neural networks with a priori information on mv, the RMSE on the mv estimates vary between $0.036 \mathrm{~cm}^{3} \mathrm{~cm}^{-3}\left(\theta=25^{\circ}\right.$ and $\left.45^{\circ}\right)$ and $0.044 \mathrm{~cm}^{3} \mathrm{~cm}^{-3}\left(35^{\circ}\right)$ for $\pm 0.5 \mathrm{~dB}$ noise condition and between $0.045 \mathrm{~cm}^{3} \mathrm{~cm}^{-3}\left(\theta=25^{\circ}\right.$ and $\left.45^{\circ}\right)$ and $0.049 \mathrm{~cm}^{3} \mathrm{~cm}^{-3}\left(\theta=35^{\circ}\right)$ for $\pm 1 \mathrm{~dB}$ noise condition. The performance of the algorithm is slightly behind at incidence angle of $35^{\circ}$. This could be explained by the fact that the sensitivity of radar signal to $\mathrm{mv}$ and $\mathrm{rms}$ is the strongest for the incidence angles of $25^{\circ}$ and $45^{\circ}$, respectively (for incidences between $25^{\circ}$ and $45^{\circ}$ ), whereas the incidence of $35^{\circ}$ allows an intermediate sensitivity of the radar signal with mv and rms. Table 2 also shows that the inversion algorithm provides un-biased soil moisture estimates.

The introduction of a priori information on one or two soil parameters (mv, rms, or $\mathrm{mv}$ and $\mathrm{rms}$ ) improves the mv estimates. This improvement reaches $0.02 \mathrm{~cm}^{3} \mathrm{~cm}^{-3}$ (RMSE) for a noise on the radar backscattering coefficients of $\pm 0.5 \mathrm{~dB}$, and $0.03 \mathrm{~cm}^{3} \mathrm{~cm}^{-3}$ for a noise of $\pm 1 \mathrm{~dB}$. For a noise of $\pm 0.5 \mathrm{~dB}$, the improvement observed on the mv estimates is of the same order in the case of a priori information on $\mathrm{mv}$ or rms. For a higher noise $( \pm 1 \mathrm{~dB})$, results show better estimates of $\mathrm{mv}$ in the case of a priori information on mv than in the case of a priori information on rms. Moreover, the results from the simulated dataset show that the introduction of a priori information on both $\mathrm{mv}$ and $\mathrm{rms}$ provides similar accuracy on the mv estimates than the case with a priori information on $\mathrm{mv}$ alone (difference lower than $0.005 \mathrm{~cm}^{3} \mathrm{~cm}^{-3}$ ). Consequently, the improvement gained by the a priori information on rms is minor.

Moreover, the performances of the neural networks were analyzed as a function of the rms and mv values (Figs. 2 and 3). For a noise of $\pm 1 \mathrm{~dB}$, results showed that for a given rms between $1.0 \mathrm{~cm}$ and $3.6 \mathrm{~cm}$, the RMSE on the mv estimates is of the same order for incidence angles between $20^{\circ}$ and $45^{\circ}$. Results show that the RMSE on mv varies slightly 

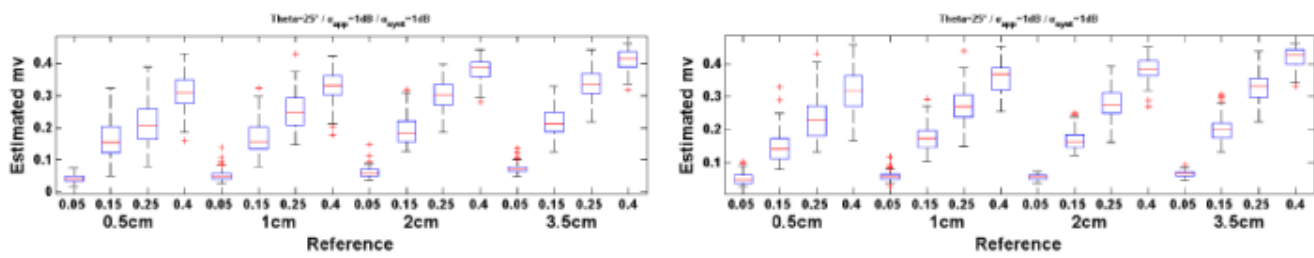

$25^{\circ}$, No a priori information on $\boldsymbol{m v}$ and $r m s$

$25^{\circ}$, A priori information on rms
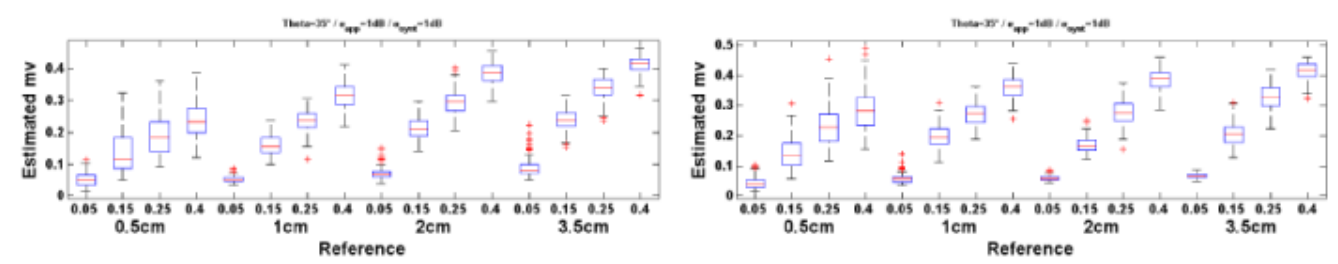

$35^{\circ}$, No a priori information on $\boldsymbol{m v}$ and $r m s$

$35^{\circ}$, A priori information on rms
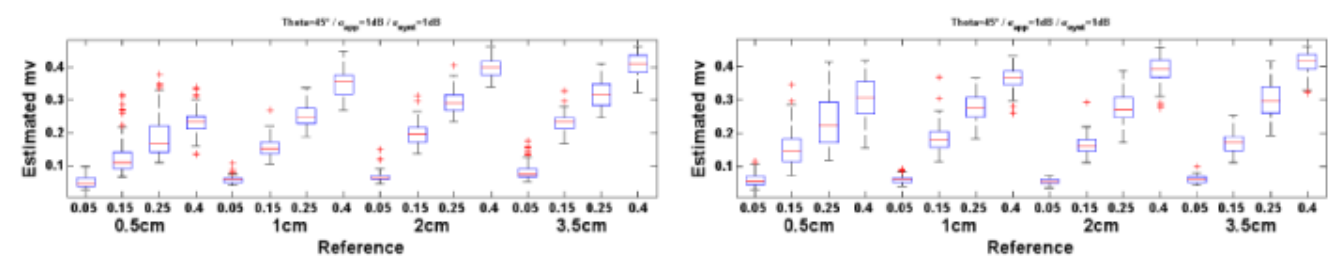

$45^{\circ}$, No a priori information on $\boldsymbol{m v}$ and $r m s$

$45^{\circ}$, A priori information on $r m s$
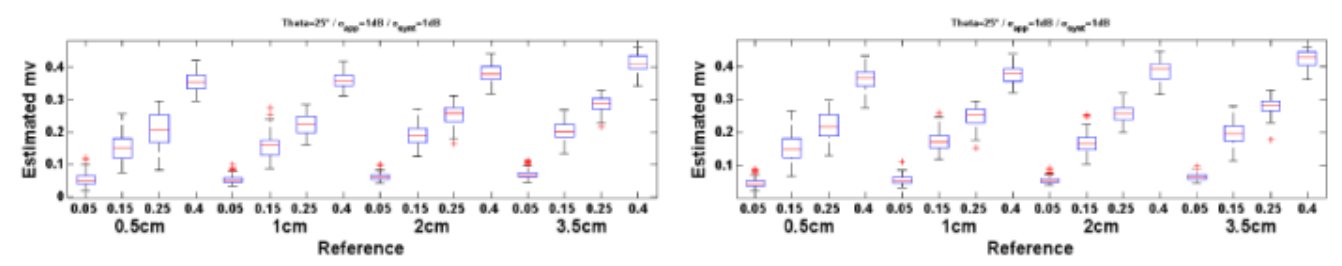

$25^{\circ}$, A priori information on $m v$

$25^{\circ}$, A priori information on $m v$ and $r m s$
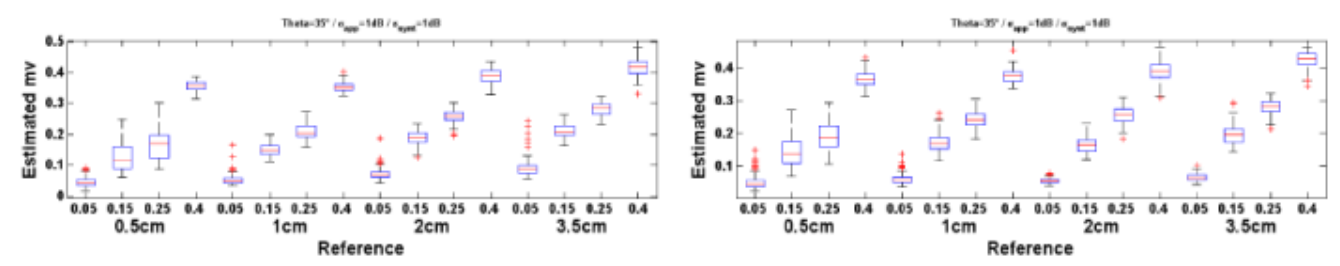

$35^{\circ}$, A priori information on $m v$

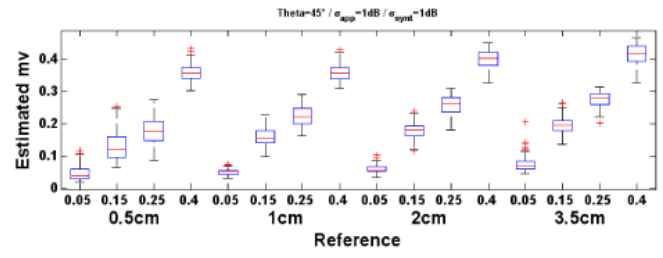

$35^{\circ}$, A priori information on $m v$ and $r m s$

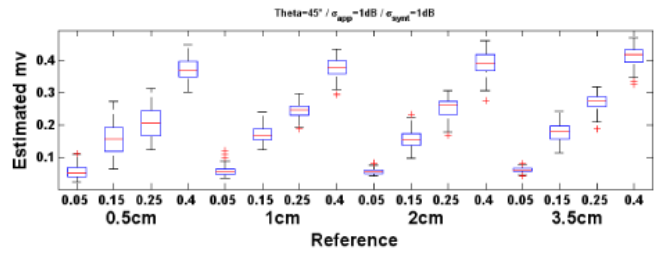

$45^{\circ}$, A priori information on $\boldsymbol{m v}$

$45^{\circ}$, A priori information on $m v$ and $r m s$

Fig. 2. Box plots of soil moisture estimates $\left(\mathrm{cm}^{3} \mathrm{~cm}^{-3}\right)$ retrieved from the synthetic dataset. Training and validation datasets correspond to a noise on the backscattering coefficients of $\pm 1 \mathrm{~dB}$. Four $\mathrm{rms}$ and four $\mathrm{mv}$ values were plotted: $\mathrm{rms}=0.5,1,2,3.5 \mathrm{~cm} ; \mathrm{mv}=0.05,0.15,0.25$, $0.40 \mathrm{~cm}^{3} \mathrm{~cm}^{-3}$. 


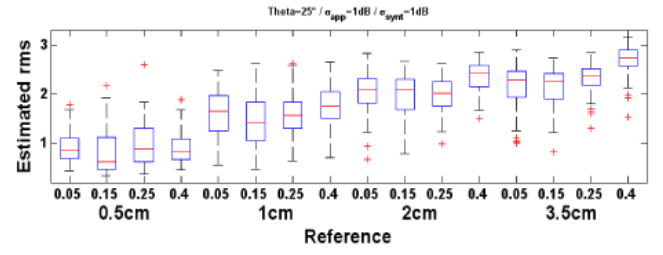

$25^{\circ}$, No a priori information on $\boldsymbol{m v}$ and $r m s$

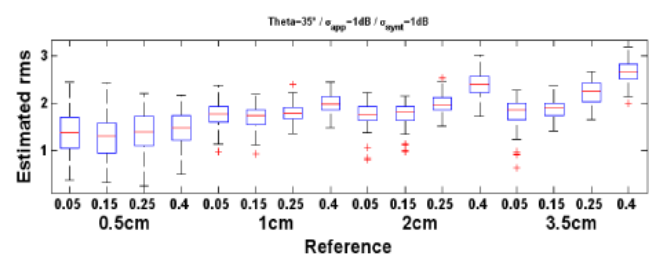

$35^{\circ}$, No a priori information on $\boldsymbol{m v}$ and $r m s$

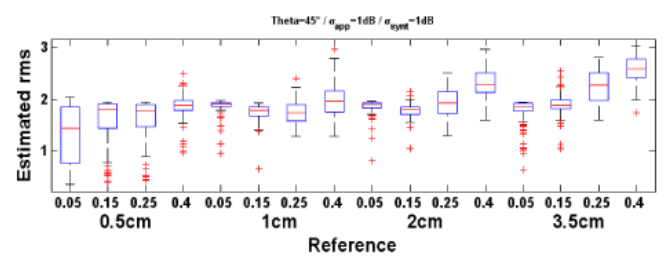

$45^{\circ}$, No a priori information on $\boldsymbol{m v}$ and $r \boldsymbol{m s}$

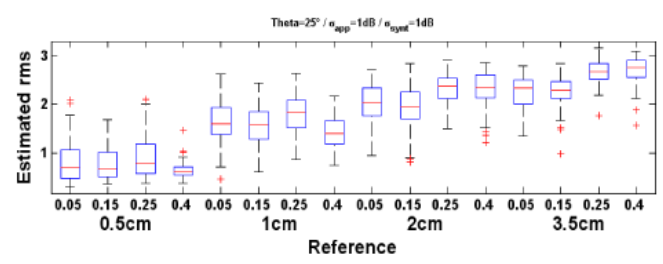

$25^{\circ}$, A priori information on $\boldsymbol{m v}$

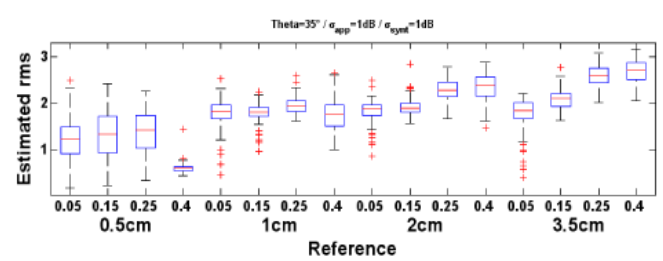

$35^{\circ}$, A priori information on $\boldsymbol{m v}$

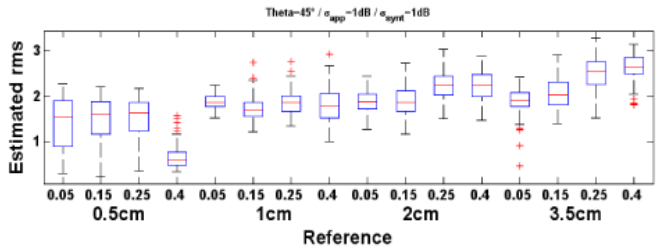

$45^{\circ}$, A priori information on $m v$

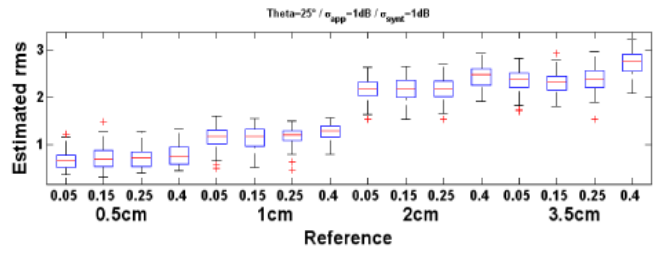

$25^{\circ}$, A priori information on $r m s$

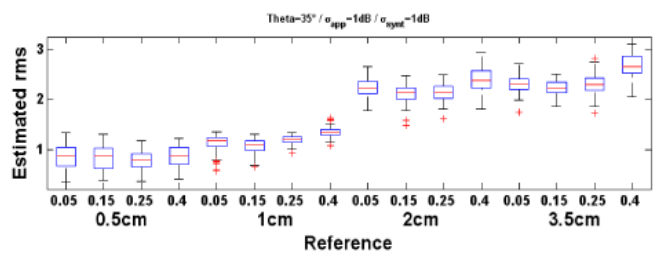

$35^{\circ}$, A priori information on $r m s$

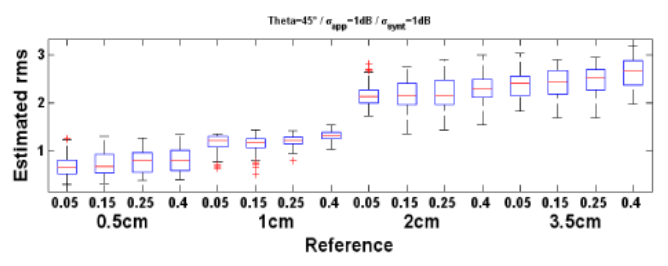

$45^{\circ}$, With a priori information on $\mathrm{rms}$

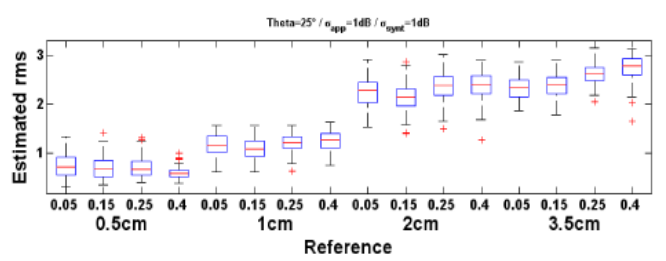

$25^{\circ}$, A priori information on $m v$ and $r m s$

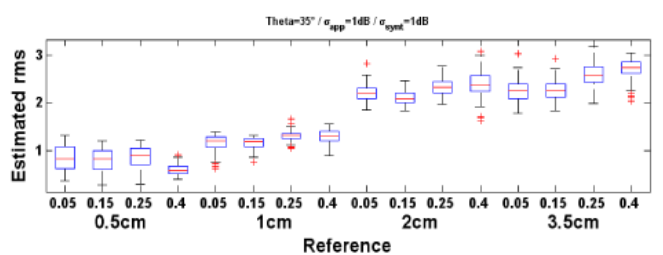

$35^{\circ}$, A priori information on $\boldsymbol{m v}$ and $r m s$

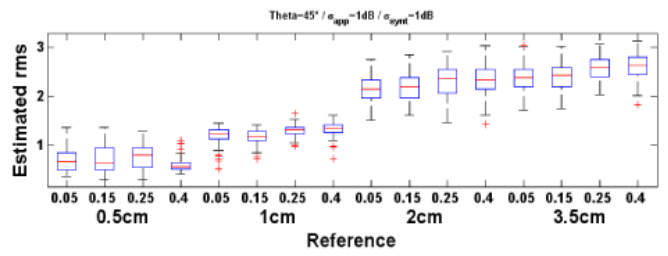

$45^{\circ}$, A priori information on $\boldsymbol{m v}$ and $r m s$

Fig. 3. Box plots of surface roughness estimates $(\mathrm{cm})$ from the synthetic dataset. Training and validation datasets correspond to a noise on the backscattering coefficients of $\pm 1 \mathrm{~dB}$. Four $\mathrm{rms}$ and four mv values were plotted: $\mathrm{rms}=0.5,1,2,3.5 \mathrm{~cm} ; \mathrm{mv}=0.05,0.15,0.25$, $0.40 \mathrm{~cm}^{3} \mathrm{~cm}^{-3}$. 
with the rms for rms between $1.0 \mathrm{~cm}$ and $3.6 \mathrm{~cm}$ (between 0.05 and $0.07 \mathrm{~cm}^{3} \mathrm{~cm}^{-3}$ in the case of no a priori information on $\mathrm{mv}$ and rms). For rms lower than $1.0 \mathrm{~cm}$, the RMSE increases with the incidence angle in the case of no a priori information on $\mathrm{mv}$ and $\mathrm{rms}$ (from $0.075 \mathrm{~cm}^{3} \mathrm{~cm}^{-3}$ to $0.12 \mathrm{~cm}^{3} \mathrm{~cm}^{-3}$ for $\left.\mathrm{rms}=0.5 \mathrm{~cm}\right)$ and decreases when the rms increases (for rms between 0.5 and $1 \mathrm{~cm}$ ). As example for an incidence angle of $45^{\circ}$, RMSE on $\mathrm{mv}$ is of $0.12 \mathrm{~cm}^{3} \mathrm{~cm}^{-3}$ for $\mathrm{rms}=0.5 \mathrm{~cm}$ and of $0.06 \mathrm{~cm}^{3} \mathrm{~cm}^{-3}$ for $\mathrm{rms}=0.9 \mathrm{~cm}$ ). In the case of a priori information on rms, the same behaviour is revealed with slightly lower RMSE values. Using the neural network developed with a priori information on $\mathrm{mv}$ alone or with a priori information on both $\mathrm{mv}$ and $\mathrm{rms}$, the RMSE on mv shows values between $0.04 \mathrm{~cm}^{3} \mathrm{~cm}^{-3}$ (for high rms) and $0.06 \mathrm{~cm}^{3} \mathrm{~cm}^{-3}$ (for low rms) for incidence angles between $20^{\circ}$ and $45^{\circ}$, and $\mathrm{rms}$ between 0.5 and $3.6 \mathrm{~cm}$.

Concerning the dependence between the RMSE on the mv estimates and the reference value of $\mathrm{mv}$, results indicate that for a noise of $\pm 1 \mathrm{~dB}$ the RMSE is about $0.02 \mathrm{~cm}^{3} \mathrm{~cm}^{-3}$ for $\mathrm{mv}=0.05 \mathrm{~cm}^{3} \mathrm{~cm}^{-3}$ with or without a priori information on the soil parameters. Moreover, weak dependence is observed between the RMSE on the mv estimates and the reference values of $\mathrm{mv}$ for $\mathrm{mv}$ between 0.05 and $0.35 \mathrm{~cm}^{3} \mathrm{~cm}^{-3}$. The RMSE is about $0.06 \mathrm{~cm}^{3} \mathrm{~cm}^{-3}$ in the case of no a priori information on the soil parameters, $0.05 \mathrm{~cm}^{3} \mathrm{~cm}^{-3}$ in the case of a priori information on $\mathrm{mv}$, and $0.04 \mathrm{~cm}^{3} \mathrm{~cm}^{-3}$ in the case of information a priori on rms alone or on both $\mathrm{mv}$ and rms. For mv between 0.35 and $0.45 \mathrm{~cm}^{3} \mathrm{~cm}^{-3}$, the RMSE is about $0.09 \mathrm{~cm}^{3} \mathrm{~cm}^{-3}$ in the case of no information a priori on the soil parameters, $0.075 \mathrm{~cm}^{3} \mathrm{~cm}^{-3}$ in the case of a priori information on $\mathrm{mv}$, and $0.06 \mathrm{~cm}^{3} \mathrm{~cm}^{-3}$ in the case of information a priori on rms alone or on both $\mathrm{mv}$ and rms.

The difference between the estimated and reference mv shows that the neural networks overestimates the mv for high rms-values $(>1.1 \mathrm{~cm})$ and underestimates it for low rmsvalues $(<1.1 \mathrm{~cm})$. Indeed, in our inversion procedure of radar signals, the $\mathrm{NN}$ estimates the rms parameter in the range 0.3 to $3.6 \mathrm{~cm}$. To estimate the rms in the case of smooth to moderate soils, the NN will propose for rms only estimated values higher than $0.3 \mathrm{~cm}$ and thus sometimes an estimate which could be higher than the optimal value. This overestimation of rms will lead to an underestimation of mv. The opposite phenomenon occurs for the estimate of high values of rms, where an overestimation of $\mathrm{mv}$ is observed.

For a given rms between $1.1 \mathrm{~cm}$ and $3.6 \mathrm{~cm}$, the bias is of the same order for incidence angles between $25^{\circ}$ and $45^{\circ}$. Moreover, the bias on the mv estimates increases with rms for rms-values between 1.1 and $3.5 \mathrm{~cm}$. For lower rms $(<1.1 \mathrm{~cm})$ and a noise of $\pm 1 \mathrm{~dB}$, the bias increases when the incidence angle increases and decreases when the rms increases between 0.5 and $1.1 \mathrm{~cm}$. The use of a priori information on mv reduces clearly the bias. It varies from -0.08 to $+0.04 \mathrm{~cm}^{3} \mathrm{~cm}^{-3}$ in the case of no a priori information on the soil parameters and from -0.02 to $+0.02 \mathrm{~cm}^{3} \mathrm{~cm}^{-3}$ in the case of a priori information on both $\mathrm{mv}$ and rms. Under- estimations between -0.06 and $-0.04 \mathrm{~cm}^{3} \mathrm{~cm}^{-3}$ on $\mathrm{mv}$ are also observed for high $\mathrm{mv}\left(>0.4 \mathrm{~cm}^{3} \mathrm{~cm}^{-3}\right)$ without or with a priori information on the soil parameters. For mv between 0.05 and $0.4 \mathrm{~cm}^{3} \mathrm{~cm}^{-3}$, overestimations on mv could reach $0.04 \mathrm{~cm}^{3} \mathrm{~cm}^{-3}$.

Moreover, the results reveal a great difficulty of estimating correctly the soil roughness. Similar accuracies on the rms estimates were obtained in the Cases 1 (no a priori information on the soil parameters) and 2 (a priori information on $\mathrm{mv}$ ), or in the Cases 3 (a priori information on rms) and 4 (a priori information rms and mv). However, the accuracy is slightly better if a priori information on the rms is available (Cases 3 and 4). Using the most favourable cases (3 and 4), the mean RMSE on the rms estimates is about $0.45 \mathrm{~cm}$ for a noise of $\pm 0.5 \mathrm{~dB}$ and $0.5 \mathrm{~cm}$ for a noise of $\pm 1 \mathrm{~dB}$. The bias between the estimated rms and the reference rms was low for all the four studied cases (between 0 and $-0.07 \mathrm{~cm}$ ).

The NNs underestimate the rms estimates for the high values of reference rms $(>2.5 \mathrm{~cm})$ and overestimates it for low and medium surface roughness $(<2.5 \mathrm{~cm})$. The use of a priori information on rms allows reducing very clearly the bias and the RMSE on rms for low reference rms values whereas the bias and the RMSE on rms stay unchanged for the high values of rms. With a priori information on $\mathrm{rms}$, the bias on the rms estimates does not exceed the $\pm 0.5 \mathrm{~cm}$ for reference rms values between 0.5 and $3.1 \mathrm{~cm}$ and is about $-1 \mathrm{~cm}$ for reference rms values about $3.6 \mathrm{~cm}$. The RMSE on the rms estimates is lower than $0.5 \mathrm{~cm}$ for reference rms lower than $3.1 \mathrm{~cm}$ and is about $1.1 \mathrm{~cm}$ for reference rms values about $3.5 \mathrm{~cm}$. The analysis of rms estimates, as a function of reference mv values, shows also that the difference between the estimated and the reference rms is unchanged with the incidence angle for a given mv. Moreover, the neural networks underestimate the rms estimates for mv lower than $0.25 \mathrm{~cm}^{3} \mathrm{~cm}^{-3}$ and overestimate for mv higher than $0.25 \mathrm{~cm}^{3} \mathrm{~cm}^{-3}$. The RMSE on the rms estimates increases slightly with the incidence angle for a given reference mv value when no a priori information on the rms was considered (from $0.6 \mathrm{~cm}$ at $25^{\circ}$ to $0.85 \mathrm{~cm}$ at $45^{\circ}$ ). With a priori information on rms, the RMSE is of the same order for all incidence angles and reference mv values (about $0.5 \mathrm{~cm}$ ).

\subsection{RADARSAT-2 dataset}

The retrieval capacity of $\mathrm{NN}$ is then analyzed using the RADARSAT- 2 dataset. Table 3 gives the statistical results obtained for the estimation of $\mathrm{mv}$ and rms according to inversion configurations 1, 2, and 4 as defined in Sect. 2.4:

- No a priori information on mv and rms

- With a priori information on mv given expert knowledge (dry to wet soils or very wet soils). The a priori information on mv is provided by an expert using meteorological data (precipitations, temperature) and terrain knowledge. The expert chooses among two 
Table 3. Inversion approach results for RADARSAT-2 data. The format of results is "a/b", where "a" corresponds to statistics using a noise of $\pm 0.5 \mathrm{~dB}$, and " $\mathrm{b}$ " corresponds to statistics using a noise of $\pm 1.0 \mathrm{~dB}$. The neural networks trained with data generated at incidence angles of $35^{\circ}$ and $45^{\circ}$ were used for images acquired at incidence angles near of $35^{\circ}$ and $45^{\circ}$, respectively.

\begin{tabular}{|c|c|c|c|c|c|c|}
\hline & \multicolumn{3}{|c|}{ Soil moisture (mv) } & \multicolumn{3}{|c|}{ Surface roughness (rms) } \\
\hline & $\operatorname{Bias}\left(\mathrm{cm}^{3} / \mathrm{cm}^{3}\right)$ & $\operatorname{RMSE}\left(\mathrm{cm}^{3} / \mathrm{cm}^{3}\right)$ & $R^{2}$ & Bias $(\mathrm{cm})$ & RMSE (cm) & $R^{2}$ \\
\hline $\begin{array}{l}\text { Without a priori informa- } \\
\text { tion on } \mathrm{mv} \text { and } \mathrm{rms}\end{array}$ & $0.029 /-0.018$ & $0.145 / 0.098$ & $0.13 / 0.29$ & $-0.41 / 0.05$ & $0.94 / 0.73$ & $0.00 / 0.02$ \\
\hline $\begin{array}{l}\text { With a priori information } \\
\text { on mv (expert knowledge) }\end{array}$ & $0.031 / 0.003$ & $0.107 / 0.065$ & $0.36 / 0.66$ & $-0.60 /-0.19$ & $1.11 / 0.69$ & $0.00 / 0.07$ \\
\hline $\begin{array}{l}\text { With a priori information } \\
\text { on mv and rms using } \alpha_{1} \\
\text { and anisotropy }\end{array}$ & $-0.012 /-0.015$ & $0.101 / 0.083$ & $0.35 / 0.49$ & $-0.73 /-0.18$ & $1.56 / 0.66$ & $0.10 / 0.13$ \\
\hline
\end{tabular}

simple configurations: (1) very wet after an intense rainy episode $\left(\mathrm{mv}>0.30 \mathrm{~cm}^{3} \mathrm{~cm}^{-3}\right)$ or (4) dry to wet soils for dates far from a rainy episode or for areas with fast drying out of soil $\left(\mathrm{mv}<0.30 \mathrm{~cm}^{3} \mathrm{~cm}^{-3}\right)$.

- With a priori information on mv and rms using the thresholds on the polarimetric parameters $\alpha_{1}$ and $A$ ( $\alpha_{1}<10^{\circ}$ and $A<0.3$ for dry to wet soils and smooth areas; $\alpha_{1}<10^{\circ}$ and $A \geq 0.3$ for dry to wet soils and rough areas; $\alpha_{1} \geq 10^{\circ}$ and $A<0.3$ for very wet soils and smooth areas; $\alpha_{1} \geq 10^{\circ}$ and $A \geq 0.3$ for very wet soils and smooth areas).

The estimations of soil moisture (mv) and surface roughness (rms) are illustrated in Figs. 4 and 5. Results show that the precision on the estimates of soil moisture is better using the neural networks trained on simulated data when $\pm 1 \mathrm{~dB}$ noise is added than using the neural networks trained with data at $\pm 0.5 \mathrm{~dB}$. This is probably due to the noise of RADARSAT-2 data, which is closer to $\pm 1 \mathrm{~dB}$ than to $\pm 0.5 \mathrm{~dB}$ (Table 3 ). Indeed, without the use of a priori information on $\mathrm{mv}$ and $\mathrm{rms}$, the RMSE decreases from $0.145 \mathrm{~cm}^{3} \mathrm{~cm}^{-3}$ (noise $0.5 \mathrm{~dB}$ ) to $0.098 \mathrm{~cm}^{3} \mathrm{~cm}^{-3}$ (noise $\pm 1 \mathrm{~dB}$ ). The introduction of a constraint on mv provides better agreement between the estimated and measured soil moisture, with a significant decrease of the bias and the RMSE on the estimation of mv. In the case of a priori information on $\mathrm{mv}$, the RMSE decreases from $0.107 \mathrm{~cm}^{3} \mathrm{~cm}^{-3}$ (noise $\pm 0.5 \mathrm{~dB}$ ) to $0.065 \mathrm{~cm}^{3} \mathrm{~cm}^{-3}$ (noise $\pm 1 \mathrm{~dB}$ ) (Table 3). Using the a priori information on $\mathrm{mv}$ and rms from the polarimetric parameters $\alpha_{1}$ and $A$, and adding noise of $\pm 1 \mathrm{~dB}$, the RMSE on the mv estimates slightly decreased from $0.098 \mathrm{~cm}^{3} \mathrm{~cm}^{-3}$ without a constraint on $\mathrm{mv}$ and $\mathrm{rms}$ to $0.083 \mathrm{~cm}^{3} \mathrm{~cm}^{-3}$ with a constraint on $\mathrm{mv}$ and rms. In conclusion, the use of expert knowledge on mv seems to be more relevant than applying the polarimetric parameters $\alpha_{1}$ and $A$. The weak improvement of $\mathrm{mv}$ and rms estimates using the polarimetric parameters in the inversion process can be explained by low dynamics of $\alpha_{1}$ and $A$ in C-band (Baghdadi et al., 2012). However, the bias is reduced by using a priori information on the soil parameters $\mathrm{mv}$ and rms (using $\alpha_{1}$ and $A$ ). The bias was about $-0.02 \mathrm{~cm}^{3} \mathrm{~cm}^{-3}$ for the case without a constraint on $\mathrm{mv}$ and $\mathrm{rms}$ and $+0.003 \mathrm{~cm}^{3} \mathrm{~cm}^{-3}$ with a priori information on $\mathrm{mv}$ (expert knowledge) with a noise of $\pm 1 \mathrm{~dB}$ (Table 3 ).

For the estimation of surface roughness, the use of neural networks built with a noise of $\pm 1 \mathrm{~dB}$ again provides better results in comparison to neural networks trained with a noise of $\pm 0.5 \mathrm{~dB}$ (Table 3 ). With a noise of $\pm 1 \mathrm{~dB}$, the results obtained for the rms estimates are practically the same for the three studied cases with an RMSE about $0.70 \mathrm{~cm}$ (Table 3). Figure 5 shows also that the estimation of rms is very difficult for high surface roughness values $(\mathrm{rms}>2 \mathrm{~cm})$. Indeed, the radar signal in C-band is very sensitive to the soil roughness only for rms values lower than $2 \mathrm{~cm}$ (Baghdadi et al., 2002b). Beyond this threshold, the radar signal increases very slightly with the rms. In Baghdadi et al. (2002b), the mean difference between the $\sigma^{\circ}$ values for $\mathrm{rms}=2 \mathrm{~cm}$ and $\mathrm{rms}=4 \mathrm{~cm}$ reaches a maximum of $1 \mathrm{~dB}$. For surface roughness lower than $2 \mathrm{~cm}$, the precision on the soil roughness estimates is better with an RMSE about $0.5 \mathrm{~cm}$ and a difference between estimated and measured rms smaller than $0.2 \mathrm{~cm}$ on average.

\subsection{Operational mapping of soil moisture using RADARSAT-2 images}

Surface soil moisture mapping was carried out over the Thau basin (France) using RADARSAT-2 images acquired between November 2010 and March 2011 (Table 1). Based on polarimetric SAR images (HH, HV and VV polarizations), the neural networks developed from IEM simulated data are used for mapping the surface soil moisture over bare soils. The neural networks trained with a noise of $\pm 1 \mathrm{~dB}$ are selected due to the better correspondence with the noise level in RADARSAT-2 imagery.

Soil moisture estimates are obtained for several mapping scales: an estimate for each bare agricultural field, an average estimate on the basin, and an estimate for each cell of 


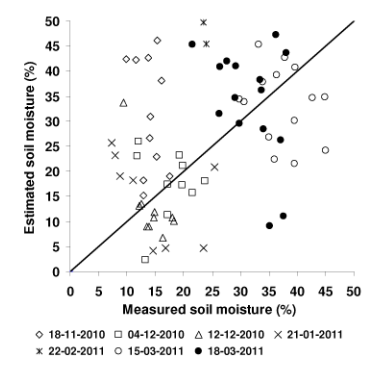

(a) Noise $= \pm 0.5 \mathrm{~dB}$

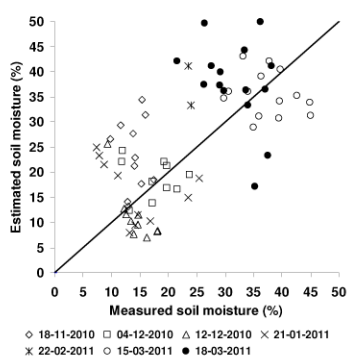

(c) Noise $= \pm 0.5 \mathrm{~dB}$

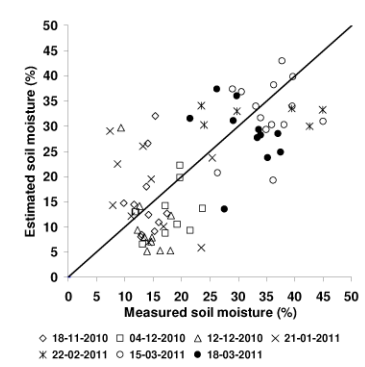

(e) Noise $= \pm 0.5 \mathrm{~dB}$

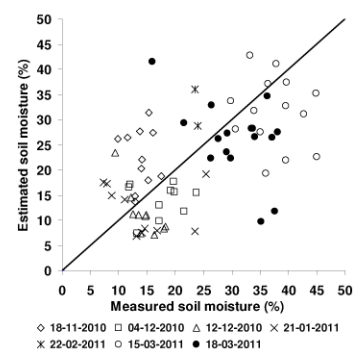

(b) Noise $= \pm 1.0 \mathrm{~dB}$

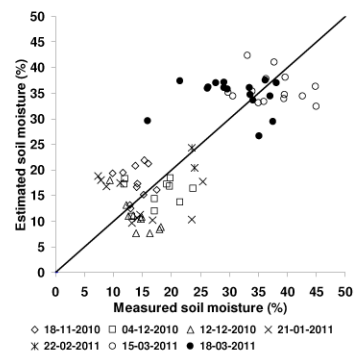

(d) Noise $= \pm 1.0 \mathrm{~dB}$

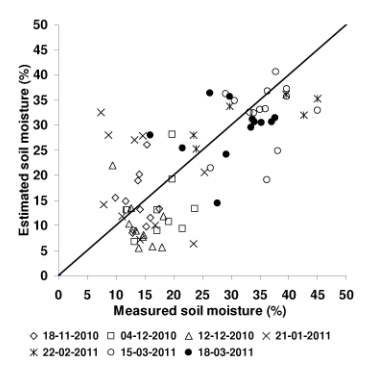

(f) Noise $= \pm 1.0 \mathrm{~dB}$

Fig. 4. Retrieved soil moisture versus in situ measurements. (a, b): without a constraint on mv and rms; (c, d): with a constraint on mv (expert knowledge); (e, f): use of $\alpha_{1}$ and anisotropy to determine the possible values of $\mathrm{mv}$ and $\mathrm{rms}$. Each point corresponds to one training plot (using the mean backscattering coefficient of all pixels of the reference plot). The reference plots are at the outside of the RADARSAT-2 image of 11 January 2011. The neural networks trained with data generated at incidence angles of $35^{\circ}$ and $45^{\circ}$ were used for images acquired at incidence angles near of $35^{\circ}$ and $45^{\circ}$, respectively.

a predefined grid. For mapping at the field scale, the radar signal is averaged for each field. The estimation of mean soil moisture on the basin scale uses the mean backscattering coefficient of all bare soil pixels present in the basin. For mapping soil moisture on grid cells of $N$ meters by $M$ meters each, the basin is subdivided in a regular grid and the mean backscattering coefficient for each grid cell is determined from averaging the values of all bare soil pixels within each grid cell.

The estimation of soil moisture is performed only on bare soils or soils with thin vegetation layer. A land use/land cover
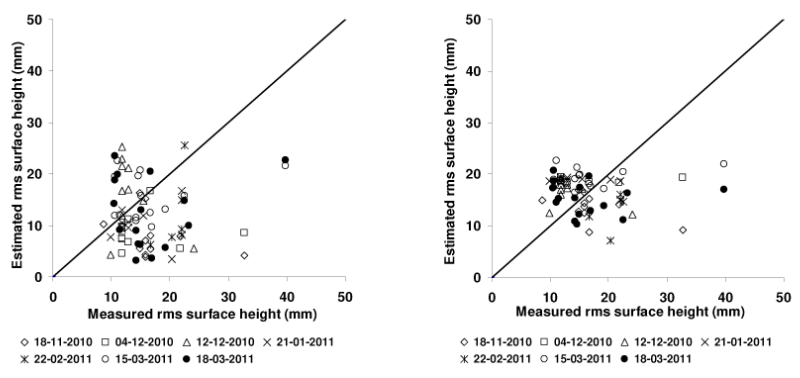

(a) Noise $= \pm 0.5 \mathrm{~dB}$

(b) Noise $= \pm 1.0 \mathrm{~dB}$
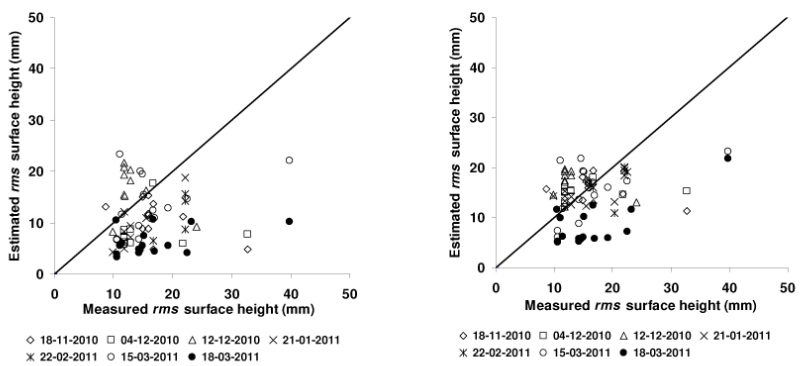

(c) Noise $= \pm 0.5 \mathrm{~dB}$

(d) Noise $= \pm 1.0 \mathrm{~dB}$
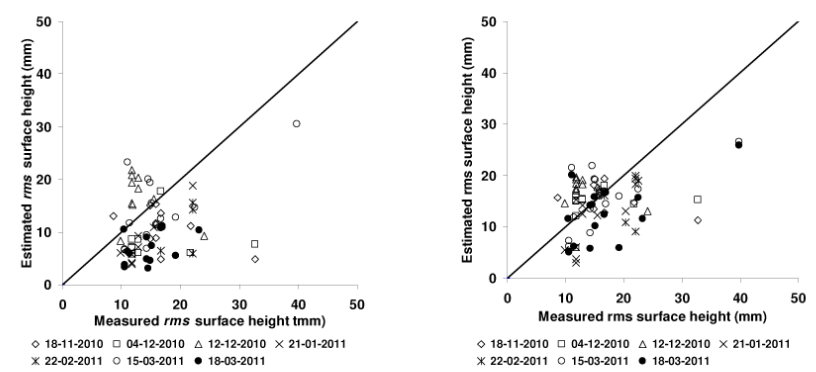

(e) Noise $= \pm 0.5 \mathrm{~dB}$

(f) Noise $= \pm 1.0 \mathrm{~dB}$

Fig. 5. Retrieved rms surface height versus in situ measurements $(\mathbf{a}, \mathbf{b})$ : without a constraint on mv and rms; (c, d): with a constraint on mv (expert knowledge); (e, f): use of $\alpha_{1}$ and anisotropy to determine the possible values of $\mathrm{mv}$ and $\mathrm{rms}$. Each point corresponds to one training plot (using the mean backscattering coefficient of all pixels of reference plot). The reference plots are at the outside of the RADARSAT-2 image of 11 January 2011. The neural networks trained with data generated at incidence angles of $35^{\circ}$ and $45^{\circ}$ were used for images acquired at incidence angles near of $35^{\circ}$ and $45^{\circ}$, respectively.

map was produced for the Thau basin using remote sensing data and ground observations (2010-2011). First, only agricultural fields intended for growing cereals (wheat) and market gardens were selected (sometimes without vegetation) the other agricultural fields. Next, the Normalized Difference Vegetation Index (NDVI) was computed using Landsat-5 optical images (December 2010, February and March 2011), and an NDVI value under an empirical threshold of 0.25 was found for mapping bare soils and areas with thin vegetation cover. For each SAR image, the bare soil map used 

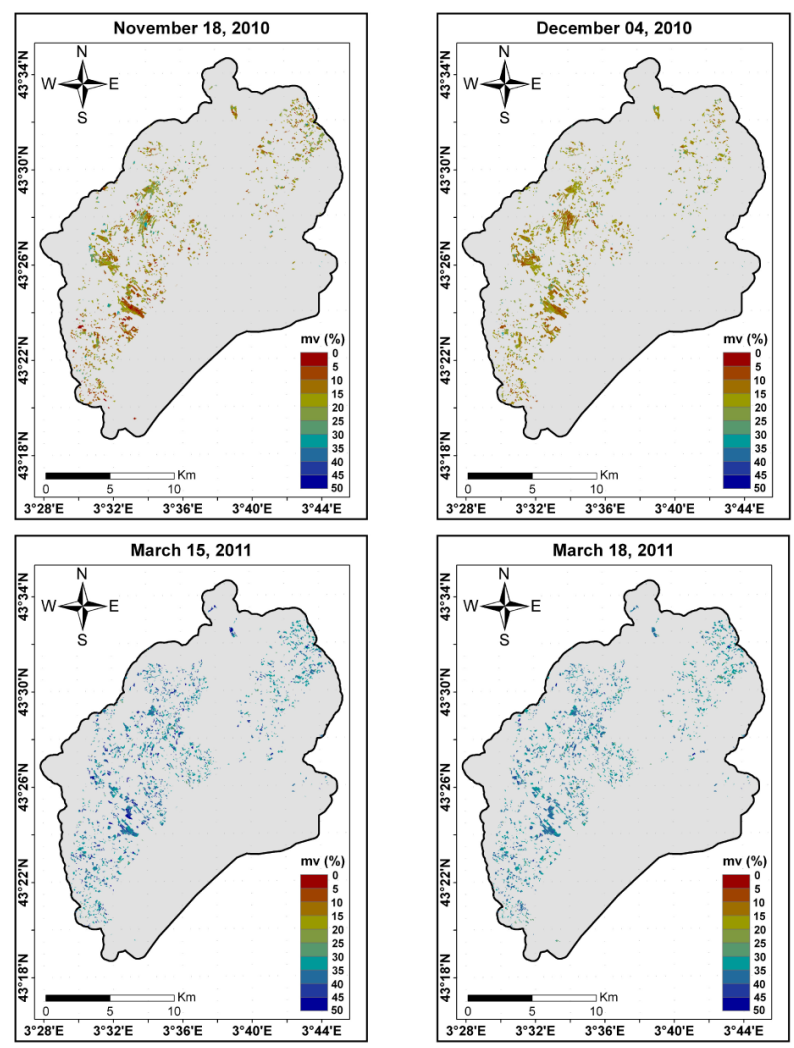

Fig. 6. Examples of soil moisture maps over bare agricultural areas for four different dates. The estimation of soil moisture was carried out for each bare agricultural parcel using expert knowledge on mv.

corresponds to the one obtained from the optical image with the closest acquisition date.

Figure 6 shows the temporal variation of soil moisture estimated by RADARSAT-2 for four different dates (18 November and 4 December 2011; 15 and 18 March). The estimation of soil moisture was carried out for each bare agricultural field using a priori information on mv based on expert knowledge or polarimetric parameters $\alpha_{1}$ and $A$. Based on the meteorological data (precipitations and temperature) over the basin (Fig. 7), the expert chooses among two simple configurations. The soils are supposed very wet if the SAR image is acquired after an intense rainy episode. In this case, the soil moisture contents will be in general estimated between 0.25 and $0.45 \mathrm{~cm}^{3} \mathrm{~cm}^{-3}$. For a SAR image acquired far from a rainy episode or in a context of fast drying out of soil (high temperatures), the expert assumes dry or wet soils with moisture contents which will be estimated lower than $0.35 \mathrm{~cm}^{3} \mathrm{~cm}^{-3}$. A priori information of very wet soils was provided for 15 and 18 March acquisitions whereas an information of dry to wet soils was given for the other images.

The comparison between soil moistures estimated from SAR images and in situ moistures shows good agreement. For example, on 18 November 2010, dry soil was observed

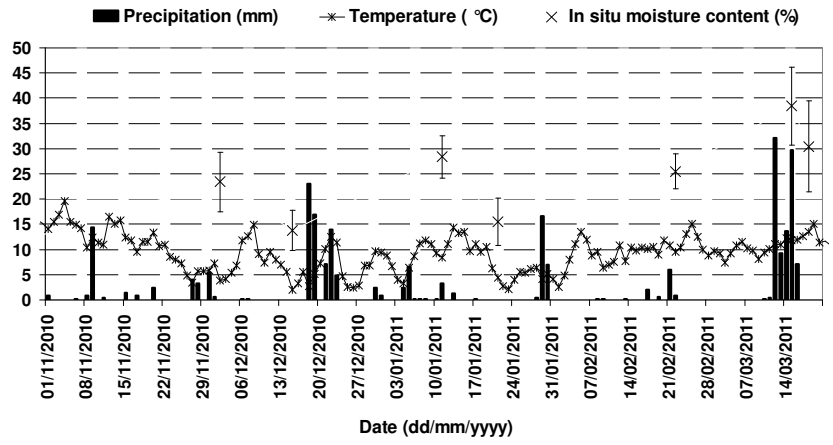

Fig. 7. Soil moisture contents from in situ measurements according to RADARSAT-2 acquisition dates, and meteorological data (daily precipitation and mean daily temperature). Precipitation and air temperature were taken from a meteorological station installed in the basin (near Sète city).

over the basin, with a low average moisture content of around $0.16 \mathrm{~cm}^{3} \mathrm{~cm}^{-3}$ (with expert knowledge on $\mathrm{mv}$ ). Indeed, no rainfalls were recorded during the eight days preceding the acquisition of this satellite image. The weak precipitation on 30 November $2010(5.4 \mathrm{~mm})$ maintained the same moisture content on 4 December as on 18 November (about $0.19 \mathrm{~cm}^{3} \mathrm{~cm}^{-3}$ ). After significant precipitation between 12 March and 15 March $2011(85 \mathrm{~mm})$, the radar soil moisture increased from $0.19 \mathrm{~cm}^{3} \mathrm{~cm}^{-3}$ on 22 February 2011 to $0.36 \mathrm{~cm}^{3} \mathrm{~cm}^{-3}$ on 15 March 2011. Radar soil moistures estimated on 18 March 2011 were lower $\left(0.34 \mathrm{~cm}^{3} \mathrm{~cm}^{-3}\right)$ than those of 15 March 2011. This tendency is completely coherent because there was no precipitation recorded between the two dates and the soil has thus started to dry off. The air temperature during the SAR acquisitions was higher than $5^{\circ} \mathrm{C}$.

Figure 8 compares the soil moisture estimates averaged on all training plots (using the mean backscattering coefficients) and the corresponding in situ measurements. Results show better precision on the soil moisture estimates when a scale larger than the plot was used (mean of all training plots for each SAR date). For each image date, the soil moisture was estimated by using the mean backscattering coefficient of all pixels present in the training plots. The difference between soil moisture estimates and in situ soil moistures is on average near zero. The RMSE is about $0.056 \mathrm{~cm}^{3} \mathrm{~cm}^{-3}$ with no a priori information on soil parameters, $0.032 \mathrm{~cm}^{3} \mathrm{~cm}^{-3}$ with expert knowledge on $\mathrm{mv}$, and $0.035 \mathrm{~cm}^{3} \mathrm{~cm}^{-3}$ using $\alpha_{1}$ and $A$.

\section{Conclusions}

The objective of this study was to assess the capacity of estimating soil moisture over bare agricultural areas using Cband polarimetric SAR. An inversion technique based on the Multi-Layer Perceptron neural network was developed 


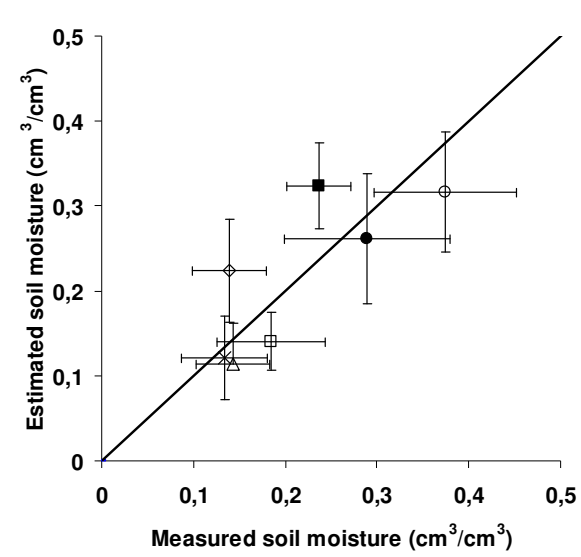

$\diamond 18 / 11 / 2010 \square 04 / 12 / 2010 \triangle 12 / 12 / 2010 \times 21 / 01 / 2011$ — 22/02/2011 $\circ$ 15/03/2011 $\bullet 18 / 03 / 2011$

\section{No a priori information on $m v$ and $r m s$}

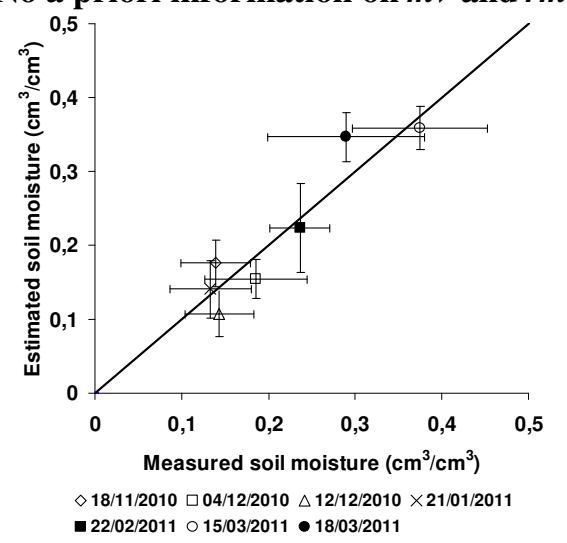

With a priori information on $m v$ (expert knowledge)

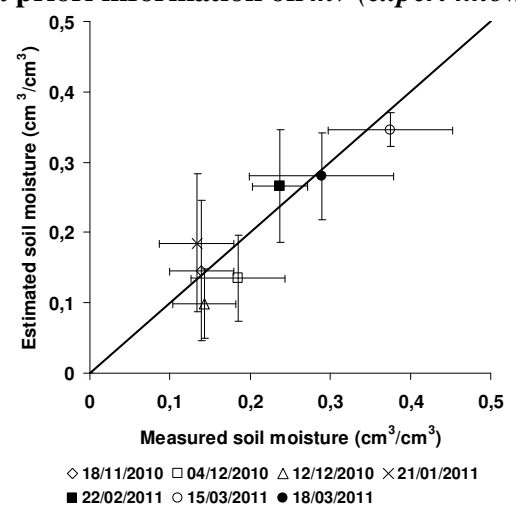

With $\alpha_{1}$ and anisotropy

Fig. 8. Comparison between the estimated mv-values and those measured. The error bars on the measured and estimated soil moisture values correspond to one standard deviation. Each point corresponds to the mean of soil moisture values of a given image date using all training plots. The reference plots are at the outside of the RADARSAT-2 image of 11 January 2011. to estimate soil surface parameters from SAR data. Neural networks (NNs) were trained with radar backscattering coefficients generated from the Integral Equation Model (IEM). The backscattering coefficients in $\mathrm{HH}, \mathrm{HV}$ and VV polarizations were simulated using the IEM model for a wide range of radar incidence angle, soil moisture (mv), and surface roughness (rms). The NNs were then applied to another simulated dataset and a real dataset composed of ten RADARSAT- 2 images in polarimetric mode to validate the inversion technique and to determine the precision on the soil moisture and surface roughness estimates.

The best mv estimation results were obtained when a priori information was given to $\mathrm{mv}$. The a priori information on $\mathrm{mv}$ can be provided by an expert using meteorological data (e.g. precipitations, temperature) and terrain knowledge (e.g. soil type). The expert chooses among two simple configurations. The soils are supposed very wet if the SAR image is acquired after an intense rainy episode, and dry or wet for SAR images acquired far from a rainy episode or in a context of fast drying out of soil (high temperatures). Moreover, the use of polarimetric parameters in the inversion procedure was tested. The polarimetric parameter $\alpha_{1}$ was used to discriminate two soil moisture classes (very wet soils, and dry to wet soils) and the anisotropy parameter $A$ to separate two soil roughnesses (smooth with $k \mathrm{rms}<1.0$ and rough with $k \mathrm{rms} \geq 1.0$ ). The inversion errors obtained with the RADARSAT-2 images on the mv estimates is about $0.065 \mathrm{~cm}^{3} \mathrm{~cm}^{-3}$ with a priori information on mv compared with $0.098 \mathrm{~cm}^{3} \mathrm{~cm}^{-3}$ without a priori information on the soil parameters. The use of polarimetric parameters slightly improves the soil moisture estimates in comparison to the case without a priori information on the soil parameters $\left(0.083\right.$ as compared to $\left.0.098 \mathrm{~cm}^{3} \mathrm{~cm}^{-3}\right)$. This is due to the weak dynamics of the polarimetric parameters with the soil parameters for the C-band.

Results show also that the estimation of soil surface roughness (rms) is possible with an accuracy around $0.5 \mathrm{~cm}$ (RMSE). The estimation is better for $\mathrm{rms}$ lower than $2 \mathrm{~cm}$. For higher $\mathrm{rms}$, the NNs underestimate the surface roughness.

The results of this study indicate that the inversion technique using data generated by the electromagnetic model IEM are able to retrieve the soil moisture and surface roughness with acceptable accuracy. These inversion results are encouraging and indicate good potential for applying a neural network for soil parameters estimation. Nevertheless, we note that the introduction of a constraint of pre-information on soil moisture improves mv estimation. The quality of the estimation of soil moisture is probably not correlated to the incidence angle of SAR images (tested between $25^{\circ}$ and $45^{\circ}$ ).

The accuracy of soil moisture content estimates obtained in this study $\left(0.065 \mathrm{~cm}^{3} \mathrm{~cm}^{-3}\right)$ could satisfy the requirements of operational users of soil moisture products. Walker and Houser (2004) found that surface soil moisture observations for satellite products must have an accuracy better 
that $0.05 \mathrm{~cm}^{3} \mathrm{~cm}^{-3}$ to positively impact soil moisture forecasts. The current or future SAR sensors (e.g. RADARSAT2, TerraSAR-X, CosmoSky-Med, Sentinel-1) can provide weekly soil moisture maps at a fine spatial scale (better than $50 \mathrm{~m})$. However, the need of hydrological and agricultural communities in terms of soil moisture accuracy and spatial and temporal scale/resolution should be analyzed in detail and compared to the potential of SAR-derived products.

Moreover, our approach could be tested on a dualpolarization SAR imagery scenario in order to evaluate its performance for the future GMES Sentinel-1 radar images.

Acknowledgements. This work has been financed by the European project CLIMB (Climate induced changes on the hydrology of Mediterranean Basins, GA: 244151) and the IRSTEA (National Research Institute of Science and Technology for Environment and Agriculture). The authors wish to thank CSA (Canadian Space Agency) for kindly providing RADARSAT-2 (SOAR-E Project 5032). Thanks are also due to Yves Gauthier, Karem Chokmani, and Monique Bernier (INRS-ETE), who very kindly provided their assistance with the procurement of RADARSAT-2 images. Thanks also to Jean Pierre Roussillon and Gilles Brocard (Syndicat Mixte $\mathrm{du}$ Bassin de Thau) for providing meteorological and topographical data for the Thau basin.

Edited by: M. Vanclooster

\section{References}

Alvarez-Mozos, J., Casali, J., Gonzalez-Audicana, M., and Verhoest, N. E. C.: Assessment of the operational applicability of RADARSAT-1 data for surface soil moisture estimation, IEEE T. Geosci. Remote Se., 44, 913-924, 2006.

Alvarez-Mozos, J., Verhoest, N. E. C., Larranaga, A., Casali, J., and Gonzalez-Audicana, M.: Influence of surface roughness spatial variability and temporal dynamics on the retrieval of soil moisture from SAR observations, Sensors, 9, 463-489, doi:10.3390/s90100463, 2009.

Atkinson, P. M. and Tatnall, A. R. L.: Neural networks in remote sensing: introduction, Int. J. Remote Se., 18, 699-709, 1997.

Baghdadi, N., Gaultier, S., and King, C.: Retrieving surface roughness and soil moisture from SAR data using neural networks, Can. J. Remote Sens., 28, 701-711, 2002a.

Baghdadi, N., King, C., Bourguignon, A., and Remond, A.: Potential of ERS and RADARSAT data for surface roughness monitoring over bare agricultural fields : application to catchments in Northern France, Int. J. Remote Sens., 23, 3427-3442, 2002 b.

Baghdadi, N., Gherboudj, I., Zribi, M., Sahebi, M., Bonn, F., and King, C.: Semi-empirical calibration of the IEM backscattering model using radar images and moisture and roughness field measurements, Int. J. Remote Sens., 25, 3593-3623, 2004.

Baghdadi, N., Holah, N., and Zribi, M.: Soil moisture estimation using multi-incidence and multi-polarization ASAR SAR data, Int. J. Remote Sens., 27, 1907-1920, 2006a.

Baghdadi, N., Holah, N., and Zribi M.: Calibration of the Integral Equation Model for SAR data in C-band and $\mathrm{HH}$ and VV polarizations, Int. J. Remote Sens., 27, 805-816, 2006 b.
Baghdadi, N., Abou Chaaya, J., and Zribi, M.: Semi-empirical calibration of the Integral quation Model for SAR data in C-band and cross polarization using radar images and field measurements, IEEE Geosci. Remote Sens. Lett., 8, 14-18, 2011.

Baghdadi, N., Cresson, R., Pottier, E., Aubert, M., Zribi, M., Jacome, A., and Benabdallah, S.: A potential use for the C-band polarimetric SAR parameters to characterise the soil surface over bare agriculture fields, IEEE T. Geosci. Remote Se., in press, 2012.

Callens, M., Verhoest, N. E. C., and Davidson, M. W. J.: Parameterization of tillage-induced single scale soil roughness from 4-m profiles, IEEE T. Geosci. Remote Sen., 44, 878-888, 2006.

Dawson, M. S., Fung, A. K., and Manry, M. T.: A robust statisticalbased estimator for soil moisture retrieval from radar measurements, IEEE T. Geosci. Remote Se., 35, 57-68, 1997.

Dubois, P., Van Zyl, J., and Engman, T.: Measuring soil moisture with imaging radars, IEEE T. Geosci. Remote Se., 33, 915-926, 1995.

Fine, T. L.: Feedforward neural networks methodology, SpringerVerlag, New York, 1999.

Fung, A. K.: Microwave Scattering and Emission Models and their Applications, Artech House, Inc., Boston, London, 573 pp., 1994.

Fung, A. K., Li, Z., and Chen, K. S.: Backscattering from a randomly rough dielectric surface, IEEE T. Geosci. Remote Se., 30, 356-369, doi:10.1109/36.134085, 1992.

Hallikaïnen, M. T., Ulaby, F. T., Dobson, F. T., El Rayes, M. C., and Wu, L. K.: Microwave dielectric behavior of wet soil. Part I: Empirical models and experimental observations, IEEE T. Geosci. Remote Se., 23, 25-34, 1985

Le Hégarat-Mascle, S., Zribi, M., Alem, F., Weisse, A., and Loumagne, C.: Soil moisture estimation from ERS/SAR data: toward an operational methodology, IEEE T. Geosci. Remote Se., 40, 2647-2658, 2002.

Le Toan, T.: Active microwave signatures of soils and crops: significant results of three years of experiments, IEEE Int. Geosci. Remote Se., Symposium, Munich, Germany, 1-4 June 1982, 2532, 1982.

Lievens, H., Vernieuve, H., Álvarez-Mozos, J., De Baets, B., Verhoest, N.E.C.: Error in radar-derived soil moisture due to roughness parametrization: an analysis based on systhetical surface profiles, Sensors, 9, 1067-1093, doi:10.3390/s90201067, 2009.

Lievens, H., Verhoest, N. E. C., De Keyser, E., Vernieuwe, H., Matgen, P., Álvarez-Mozos, J., and De Baets, B.: Effective roughness modelling as a tool for soil moisture retrieval from C- and L-band SAR, Hydrol. Earth Syst. Sci., 15, 151-162, doi:10.5194/hess15-151-2011, 2011.

Marquardt, D. W.: An Algorithm for the Estimation of Nonlinear Parameters, Journal of the Society for Industrial and Applied Mathematics, 11, 431-441, 1963.

Mattia, F., Satalino, G., Dente, L., and Pasquariello, G.: Using a priori information to improve soil moisture retrieval from ENVISAT ASAR AP data in semi-arid regions, IEEE T. Geosci. Remote Se., 44, 900-912, 2006.

Mattia, F., Satalino, G., Pauwels, V. R. N., and Loew, A.: Soil moisture retrieval through a merging of multi-temporal L-band SAR data and hydrologic modelling, Hydrol. Earth Syst. Sci., 13, 343356, doi:10.5194/hess-13-343-2009, 2009. 
Merzouki, A., McNairn, H., and Pacheco, A.: Mapping soil moisture using RADARSAT-2 data and local autocorrelation statistics, IEEE Journal of Selected Topics in Applied Earth Observations and Remote Sensing, 4, 128-137, doi:10.1109/JSTARS.2011.2116769, 2011.

Moran, M. S., Peters-Lidard, C. D., Watts, J. M., and McElroy, S.: Estimating soil moisture at the watershed scale with satellitebased radar and land surface models, Can. J. Remote Se., 30, 805-826, 2004.

Notarnicola, C., Angiulli, M., and Posa, F.: Soil moisture retrieval from remotely sensed data: neural network approach versus Bayesian method, IEEE T. Geosci. Remote Se., 46, 547-557, 2008.

Oh, Y.: Quantitative retrieval of soil moisture content and surface roughness from multipolarized radar observations of bare soil surfaces, IEEE T. Geosci. Remote Se., 42, 596-601, 2004.

Oh, Y. and Kay, Y.: Condition for precise measurement of soil surface roughness, IEEE T. Geosci. Remote Se., 36, 691-695, 1998.

Oh, Y., Sarabandi, K., and Ulaby, F. T.: An empirical model and an inversion technique for radar scattering from bare soil surface, IEEE T. Geosci. Remote Se., 30, 370-381, 1992.

Oh, Y., Sarabandi, K., and Ulaby, F. T.: Semi-empirical model of the ensemble-averaged differential Mueller matrix for microwave backscattering from bare soil surfaces, IEEE T. Geosci. Remote Se., 40,1348-1355, 2002.

Paloscia, S., Macelloni, G., Santi, E., and Tedesco, M.: The capability of microwave radiometers in retrieving soil moisture profiles: an application of Artificial Neural Networks, Proceeding IEEEIGARSS, Firenze, Italy, 3, 1390-1392, 2002.

Paloscia, S., Pampaloni, P., Pettinato, S., and Santi, E.: A comparison of algorithms for retrieving soil moisture from ENVISAT/ASAR images, IEEE T. Geosci. Remote Se., 46, 32743284, doi:10.1109/TGRS.2008.920370, 2008.

Paloscia, S., Pampaloni, P., Pettinato, S., and Santi, E.: Generation of soil moisture maps from ENVISAT/ASAR images in mountainous areas: a case study, Int. J. Remote Se., 31, 2265-2276, 2010.

Rahman, M. M., Moran, M. S., Thoma, D. P., Bryant, R., Holifield, C. D., Jackson, T., Orr ,B. J., and Tischler, M.: Mapping surface roughness and soil moisture using multi-angle radar imagery without ancillary data, Remote Sens. Environ., 112, 391-402, 2008.

Rakotoarivony, L., Taconet, O., Vidal-Madjar, D., Bellemain, P., and Benallègue, M.: Radar backscattering over agricultural bare soils, J. Electromagne. Wave., 10, 187-209, 1996.
Ripley, B. D.: Pattern Recognition and neural networks, Cambridge University Press, Cambridge, 1996.

Santi, E., Paloscia, S., Pampaloni, P., Pettinato, S., and Poggi, P.: Retrieval of Soil Moisture from Envisat ASAR Images: A Comparison of Inversion Algorithms. Proceedings of the 2004 Envisat \& ERS Symposium (ESA SP-572), 6-10 September 2004, Salzburg, Austria, 2004.

Satalino, G., Mattia, F., Davidson, M., Le Toan, T., Pasquariello, G., and Borgeaud, M.: On current limits of soil moisture retrieval from ERS-SAR data, IEEE T. Geosci. Remote Se., 40 ,24382447, 2002.

Srivastava, H. S., Patel, P., Manchanda, M. L., and Adiga, S.: Use of multi-incidence angle RADARSAT-1 SAR data to incorporate the effect of surface roughness in soil moisture estimation, IEEE T. Geosci. Remote Se., 41, 1638-1640, 2003.

Ulaby, T., Batlivala, P. P., and Dobson, M. C.: Microwave Backscatter Dependence on Surface Roughness, Soil Moisture, and Soil Texture: Part I-Bare Soil, IEEE T. Geosci. Remote Se., 16, I286295, 1978.

Verhoest, N. E. C., De Baets, B., Mattia, F., Satalino, G., Lucau, C., Defourny, P.: A possibilistic approach to soil moisture retrieval from ERS synthetic aperture radar backscattering under soil roughness uncertainty, Water Resour. Res., 43, W07435, doi:10.1029/2006WR005295, 2007.

Verhoest, N. E. C., Lievens, H., Wagner, W., Álvarez-Mozos, J., Moran, S., and Mattia, F.: On the Soil Roughness Parameterization Problem in Soil Moisture Retrieval of Bare Surfaces from Synthetic Aperture Radar, Sensors, 8, 4213-4248, doi:10.3390/s8074213, 2008.

Walker, J. P. and Houser, P. R.: Requirements of a global nearsurface soil moisture satellite mission: Accuracy, repeat time, and spatial resolution, Adv. Water Res., 27, 785-801, 2004.

Zribi, M. and Dechambre, M.: A new empirical model to retrieve soil moisture and roughness from C-band radar data, Remote Sens. Environ., 84, 42-52, 2002.

Zribi, M., Taconet, O., Le Hegarat-Mascale, S., Vidal-Madjar, D., Emblanch, C., Loumagne, C., and Normand, M.: Backscattering behavior and simulation: comparison over bare soils using SIRC/X-SAR and ERASME 1994 data over Orgeval, Remote Sens. Environ., 59, 256-266, 1997. 